\title{
Fluid Flow and Leakage Assessment Through an Unlined/Shotcrete Lined Pressure Tunnel: A Case from Nepal Himalaya
}

\author{
Krishna Kanta Panthi ${ }^{1} \cdot$ Chhatra Bahadur Basnet ${ }^{2}$
}

Received: 20 May 2020 / Accepted: 15 December 2020 / Published online: 9 February 2021

(c) The Author(s) 2021

\begin{abstract}
The use of unlined/shotcrete lined pressure tunnels and shafts are cost-effective solutions for a hydropower project and are being implemented worldwide. To implement this concept, the ground conditions at the area of concern should be favorable regarding minimum principal stress magnitude, which should be higher than hydrostatic water head acting on the tunnel periphery. In addition, the rock mass should be relatively unjointed or joints in the rock mass should be relatively tight. Among the most important issues in the design of unlined/shotcrete lined pressure tunnels is the extent of hydraulic jacking and water leakage out of the tunnel during operation. This manuscript first presents fluid flow and potential hydraulic jacking assessment of two selected locations of the headrace tunnel of Upper Tamakoshi Hydroelectric Project (UTHP) in Nepal using the UDEC. It is noted here that the $7960 \mathrm{~m}$ long headrace tunnel will experience a hydrostatic water head that will vary from 2.9 to 11.5 bars $(0.29-1.15 \mathrm{MPa})$. The headrace tunnel is supported by sprayed concrete (shotcrete) in combination with systematic rock bolts in the tunnel walls and crown. The invert of the tunnel and few hundred meters downstream end (at surge shaft area) of the headrace tunnel is being concrete lined after the completion of all other works. The qualitative fluid flow assessment carried out using UDEC indicated considerable pressure built-up in the joint systems suggesting potential hydraulic jacking. This was especially the case at the downstream segment (downstream from chainage $7100 \mathrm{~m}$ ) of the headrace tunnel. The manuscript further presents the quantitative results of water leakage estimation from the headrace tunnel carried out using Panthi (Panthi KK (2006) Analysis of engineering geological uncertainties related to tunnelling in Himalayan rock mass conditions. PhD Thesis, NTNU, Trondheim, Norway;Panthi, Note on estimating specific leakage using Panthi's approach, NTNU, Trondheim, 2010;) approach. The leakage assessment carried out indicated an average specific leakage of about $2.5 \mathrm{l} / \mathrm{min} / \mathrm{m}$ tunnel, which may result in over $210 \mathrm{l} / \mathrm{s}$ leakage from the headrace tunnel. The evaluation also indicated that the outer reach $(860 \mathrm{~m}$ downstream segment) of the headrace tunnel after chainage $7100 \mathrm{~m}$ seems extremely vulnerable and over 80 1/s water leakage may occur only from this headrace tunnel segment during operation of the hydropower plant.
\end{abstract}

Keywords Himalayan geology and tectonics · Unlined or shotcrete lined pressure tunnel · Fluid flow analysis · Discontinuous model $\cdot$ Hydraulic jacking $\cdot$ And water leakage

\section{Introduction}

Optimum, cost-effective and long-term stabile headrace tunnels are the key to the successful development of hydropower plants. Unlined or shotcrete lined pressure tunnels are

Krishna Kanta Panthi

krishna.panthi@ntnu.no

1 Norwegian University of Science and Technology (NTNU), Trondheim, Norway

2 NEA Engineering Company Ltd, Kathmandu, Nepal used as water conveyance system of the hydropower projects worldwide due to cost effectiveness compared to concrete or steel-lined tunnels. Implementation of unlined or shotcrete lined pressure tunnels, however, depend on the ground conditions prevailing in the area of concern. The Norwegian confinement and minimum principal stress criteria are amongst the most popular design criteria adopted in locating unlined or shotcrete lined pressure tunnels and shafts (Broch 1982; Panthi 2014; Palmstrom and Broch 2017; Basnet and Panthi 2018a). The Norwegian confinement criteria mainly depend on the topography of the area and the density of rock in question. On the other hand, the minimum principal 
stress criterion depends on the topography, density of rock in question and the geo-tectonic environment of the area where unlined or shotcrete lined pressure tunnels will be located.

The magnitude of minimum principal stress (main parameter of stress criterion) is estimated by both measurements and numerical analysis. The measured stress magnitude in one location represents relatively small area of the topography. Therefore, it is important that a considerable number of measurements are required to assure whether stress level is enough or not for the implementation of unlined or shotcrete lined pressure tunnel concept. Alternatively, a comprehensive numerical modeling analysis may be used to estimate the stress state of the whole pressure tunnel alignment based on measured in-situ stress information at the downstream end of the headrace tunnel where maximum hydrostatic pressure will act during operation of the plant. Mostly, the numerical modelling is carried out by considering rock mass as a homogeneous, isotropic and elastic material. However, while carrying out stress state analysis, it is also possible to include large scale discontinuities in the model as have been demonstrated by Basnet and Panthi $(2018 b, 2019,2020)$. It is noted here that consideration of large-scale discontinuities may not fully represent the real situation since small scale discontinuities such as local weakness and shear zones or bands may also cause considerable spatial variation in the in-situ stress. The situation becomes even challenging when such small-scale discontinuities interact with the pressurized water from the unlined or shotcrete lined tunnel.

A shotcrete lined pressure tunnel is being implemented in the headrace tunnel system of Upper Tamakoshi Hydroelectric Project (UTHP) in Nepal. The headrace tunnel is lined with shotcrete (sprayed concrete) in the walls and crown, whereas the invert of the tunnel and few 100-meters downstream end (around surge shaft area) of the headrace tunnel is being concrete lined. Since sprayed concrete is a permeable material, the shotcrete lined pressure tunnel is in principal considered to be similar as an unlined tunnel. Basnet and Panthi (2020) used Norwegian confinement criteria to study the feasibility of unlined or shotcrete lined pressure tunnel at UTHP. The results showed that the whole length of headrace tunnel alignment is safe against hydraulic jacking with a factor of safety exceeding 3.5. The in-situ stress state analysis, on the other hand, showed some critical locations of the headrace tunnel, such as weakness zones and downstream stretch of the headrace tunnel where maximum hydrostatic water head will prevail during operation, the factor of safety was found to be less than the minimum required value of 1.3. The detail rock engineering assessment carried out by Basnet and Panthi (2020) indicated that the geological features consisting off local weakness zones, shear bands, unfavorable joints are critical features for unlined pressure tunnels. Therefore, the stress state analysis carried out for the UTHP was found not enough to address the behavior of geological features when exposed to full hydrostatic pressure during operation of the hydropower plant. Consequently, hydromechanical coupling assessment was needed to define the impact of the fluid flow on the mechanical behavior of the joint systems in the rock mass.

The fluid flow characteristic of the rock mass is mainly governed by the permeability of joints and discontinuities. In an unlined or shotcrete lined pressure tunnel, water gives pressure $(\mathrm{Pw})$ to the rock mass equivalent to a hydrostatic water head $(H)$. The interaction between water pressure and joints in the rock mass will therefore govern the fluid flow capacity, which is termed as hydraulic conductivity. This manuscript presents the results of fluid flow behavior assessment carried out for the joint systems in the rock mass at two selected locations of the headrace tunnel alignment of UTHP project. A discontinuous 2-D model (UDEC) developed by Itasca (2017) was used to analyze the fluid flow through the joints. Hydro-mechanical coupling was used to simulate the impact of fluid pressure on the in-situ stress state and impact of stress change on the fluid flow pattern or fluid pressure. Rock mechanical parameters required for the analysis were estimated based on field test, field mapping and laboratory testing. Parameters which were not possible to estimate using field test, field mapping and laboratory testing were appraised using available literatures. The results of fluid flow analysis were finally used to assess possible hydraulic jacking. Since fluid flow analysis using UDEC provides a qualitative assessment on potential leakage and the detail rock engineering assessment along the headrace tunnel indicated that the geological features such as small scale weakness and shear zones or shear bands and joints in the unfavorable direction from where water may leak during hydropower plant operation, it was felt essential to carry out a study on the potential leakage from the headrace tunnel during operation when maximum up to $115 \mathrm{~m}$ (11.5 bars) hydrostatic water head will be acting at the headrace tunnel. Hence, Panthi $(2006,2010)$ approach of leakages assessment was used to estimate the water leakage out from the headrace tunnel of UTHP project.

\section{Brief Review on Fluid Flow and Leakage}

The rock mass is composed of both intact rock and discontinuities. Excluding some high-porosity rocks such as young sandstones and certain volcanic rocks, most of the intact rocks have in general very low porosity. The permeability of rock mass is therefore governed by discontinuities in the rock mass. The fluid flows through discontinuities and the extent of flow (the permeability) depends on the characteristics of discontinuities in the rock mass.

In an unlined or shotcrete lined pressure tunnel, water gives pressure $(\mathrm{Pw})$ to the rock mass equivalent to the 
hydrostatic water head $(H)$ as shown in Fig. 1. The rock mass behaves differently when it is exposed to water pressure. The interaction between water pressure and rock mass is therefore an important issue for unlined or shotcrete lined pressure tunnel. Since the rock mass has joints and discontinuities, the extent of fluid flow is governed by the ability of joints and discontinuities to carry fluid.

Fluid flow through joints is in general non-laminar and unevenly distributed in the joints due to roughness and infilling condition of the joint walls. However, it is difficult to mathematically express governing laws for such turbulent flow through the joints. For simplicity, the fluid flow through joints is assumed to be laminar and represented by Darcy's equation (Eq. 1).

$v=k \times i$,

where $v$ is the flow velocity $(\mathrm{m} / \mathrm{s}), k$ is the hydraulic conductivity $(\mathrm{m} / \mathrm{s})$ and $i$ is the hydraulic gradient. If the joint surface is assumed to be planner, the flow may be idealized by means of the parallel plate model as suggested by Louis (1969). The joint hydraulic conductivity is then expressed by Eq. 2 and flow rate per unit width can thus be represented by Eq. 3 .

$k=\frac{a^{2} \times \gamma}{12 \mu}$,

$q=-k_{j} \times a^{3} \times \frac{\Delta P}{l}$

$k_{j}=\frac{1}{12 \mu}$,

where $a$ is the joint hydraulic aperture, $k_{j}$ is a permeability factor (Eq. 4), $\gamma$ is the unit weight of the fluid/water and $\mu$ is the dynamic viscosity of water which is equal to $1.306 \times 10^{-3} \mathrm{~Pa}$-s at $10^{\circ} \mathrm{C}$ (Kestin et al. 1978). In UDEC model, $\Delta P$ is the fluid pressure drop when fluid flows between two adjacent flow domains as shown in Fig. 1 (right), where $l$ is the length assigned to the contact between the domains. It is now clear that the flow is governed by the pressure differential between adjacent domains.

Since the permeability factor is constant for each type of fluid at a certain temperature, the flow rate through joints are mostly dependent on the joint aperture and fluid pressure drop between two successive domains. In UDEC model, both joint aperture and pressure drop are updated in each cycle of the solution with hydro-mechanical coupling. The contact hydraulic aperture is thus calculated by Eq. 5 in each cycle.

$a=a_{0}+u_{n}$,

where $a_{0}$ is the joint aperture at zero normal stress, and $u_{\mathrm{n}}$ is the joint normal displacement (positive denoting opening). In UDEC model, a minimum value of residual aperture $\left(a_{\text {res }}\right)$ is assumed for the aperture below which mechanical closure does not affect contact permeability. Hydraulic jacking develops in joints in the rock mass when water pressure exceeds total normal stress increasing joint aperture and thus conductivity, which results in larger flow rate towards the rock mass (Lamas et al. 2014). UDEC model can thus be used to assess the possibility of hydraulic jacking in addition to fluid flow through the joints.

According to Panthi (2006), among the most important aspects of unlined or shotcrete lined water tunnel concept is the control of water leakage while tunnel in operation at full hydrostatic pressure and limiting the leakage within the acceptable limit. The leakage limit for unlined or shotcrete lined water tunnel maybe defined maximum up to
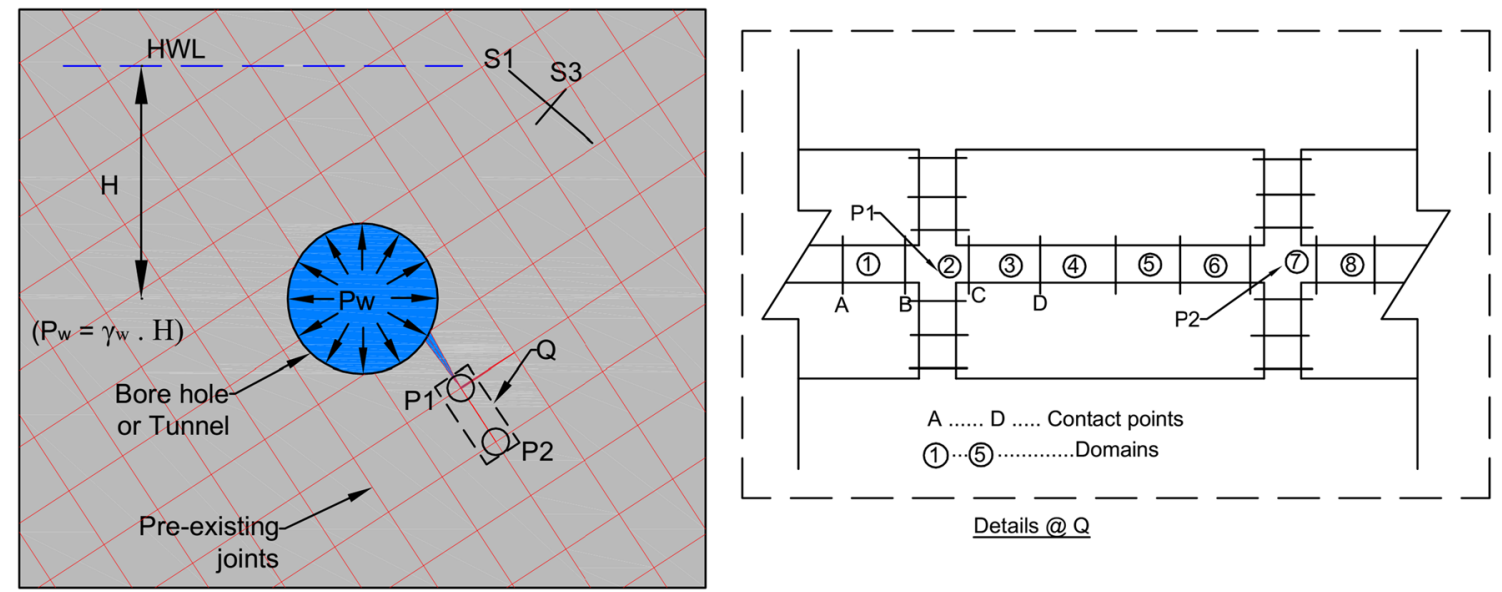

Fig. 1 Idealized sketch describing fluid flow in the jointed rock mass. In the figure, HML is headwater level and $\gamma_{\mathrm{w}}$ is unit weight of water, S1 is maximum principal stress, $\mathrm{S} 3$ is minimum principal stress 
1.51 per minute per meter tunnel. Panthi (2006) emphasizes that the permeability condition in the rock mass mainly depends on the degree of jointing and condition within different joint sets represented by joint aperture, infilling conditions, spacing of the must unfavorable joint set, joint persistence, hydrostatic water pressure that prevails in the rock mass domain and the shortest distance from the water tunnel to the topographic slope surface.

The main difficulty in leakage assessment is the quantification of possible water leakage during operation of the pressure tunnels of hydropower projects. To address this difficulty, Panthi (2006) exploited comprehensive data records of certain Q-value (Barton et al, 1974) parameters and systematic water leakage test carried out ahead of the headrace tunnel face during the excavation of Khimti I hydropower project in Nepal. A semi-empirical solution was proposed by Panthi (2006) to estimate the specific leakage $\left(q_{t}\right.$ in $\left.1 / \mathrm{min} / \mathrm{m}\right)$ from an unlined or shotcrete lined pressure tunnel (Eq. 6).

$q_{t}=f_{a} \times H \times \frac{J_{n} \times J_{r}}{J_{a}}$,

where $f_{a}$ is a joint permeability factor with unit $1 / \mathrm{min} / \mathrm{m}^{2}$. This factor is related to the physical condition of the joint sets, particularly, joint spacing and persistence, and to the shortest distance from tunnel to surface topography to the valley side slope. $H$ is the hydrostatic water head (Fig. 1), $J_{n}$ is joint set number, $J_{r}$ is joint roughness number and $J_{a}$ joint alteration number of the Q-system of rock mass classification. As can be seen in Eq. 6, parameters $H, J_{n}$ and $J_{r}$ are directly proportional and tend to increase the intensity of leakage while the parameter $J_{a}$ tends to decrease the leakage.

For headrace tunnel of Khimti I Hydropower Project in Nepal with a low hydrostatic head (maximum up to 4 bars) and a fairly schistose rock mass, the joint permeability factor $\left(f_{a}\right)$ varied from 0.03 to 0.12 (Panthi and Nilsen, 2010). According to Panthi (2010), the value of $f_{a}$ shall decrease from 0.03 further down to its minimum up to 0.001 upon a decrease in joint persistence, increase in joint spacing and confinement from the lateral rock cover and hence, the joint permeability factor $\left(f_{a}\right)$ can be quantified using Eq. 7.

$f_{a}=\mathcal{L} \times \frac{J_{p}}{D \times J_{s}}$

where, $\mathcal{L}$ is equivalent to 1 lugeon with a unit $11 / \mathrm{mim} / \mathrm{m}, J_{p}$ is joint persistence (maximum up to $25 \mathrm{~m}$ ) and $J_{s}$ is joint spacing of the most frequently occurring systematic joint set, and $D$ is the shortest distance from valley side roof (crown) of the tunnel to rock slope topography to valley side (Fig. 2).

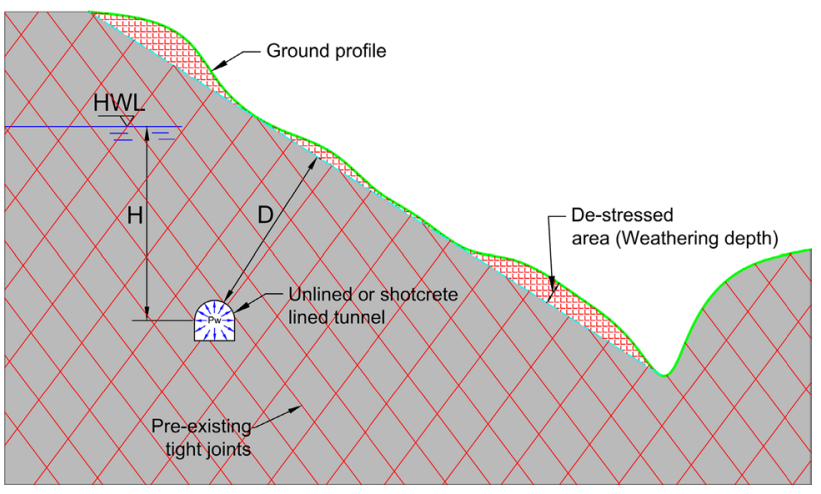

Fig. 2 Idealized topographic arrangement explaining D according to Panthi (2010)

\section{Brief on Upper Tamakoshi Project}

\subsection{UTHP Project}

The Upper Tamakoshi Hydroelectric Project (UTHP) is located at about $90 \mathrm{~km}$ northeast from Kathmandu, Nepal (Fig. 3a). The project has an installed capacity of $456 \mathrm{MW}$ and exploits design discharge of $66 \mathrm{~m}^{3} / \mathrm{sec}$ and $822 \mathrm{~m}$ gross hydrostatic water head. The project consists of a diversion dam, two settling basins, a medium to high-pressure headrace tunnel, two vertical penstock shafts, underground powerhouse, tailrace and access tunnels (Fig. $3 \mathrm{~b}$ and c). From pre-feasibility study in 2001 to until 2014, there have been several design changes in locating pressurized headrace tunnel alignment of the UTHP. The latest alignment of the headrace tunnel is shown in Fig. 3b (plan) and c (profile). The total length of the headrace tunnel is about $7960 \mathrm{~m}$, and the tunnel is designed with inverted-D shape having crosssectional area of about $32 \mathrm{~m}^{2}$ (tunnel width of $6 \mathrm{~m}$ ). The excavation of the headrace tunnel was completed in 2018 and is mainly supported with steel fiber shotcrete in combination with systematic bolting. The invert of the tunnel and a short downstream segment close to surge shaft area are being concrete lined after all other construction activities were completed. The maximum hydrostatic water head $(H)$ at the downstream end of the headrace tunnel will reach to about $115 \mathrm{~m}$ giving a pressure of $1.15 \mathrm{MPa}$ (11.5 bars).

\subsection{Geological Conditions}

Geologically, Tamakoshi project is located in the Higher Himalayan Tectonic Formation of eastern Nepal (Panthi and Basnet 2017). Rock mass in this formation is mainly characterized by Precambrian high-grade metamorphic rocks consisting gneiss, quartzite, marbles, magmatite and granitic gneiss having the quality of rock mass comparable to the Scandinavian hard rocks. The detailed geological mapping 

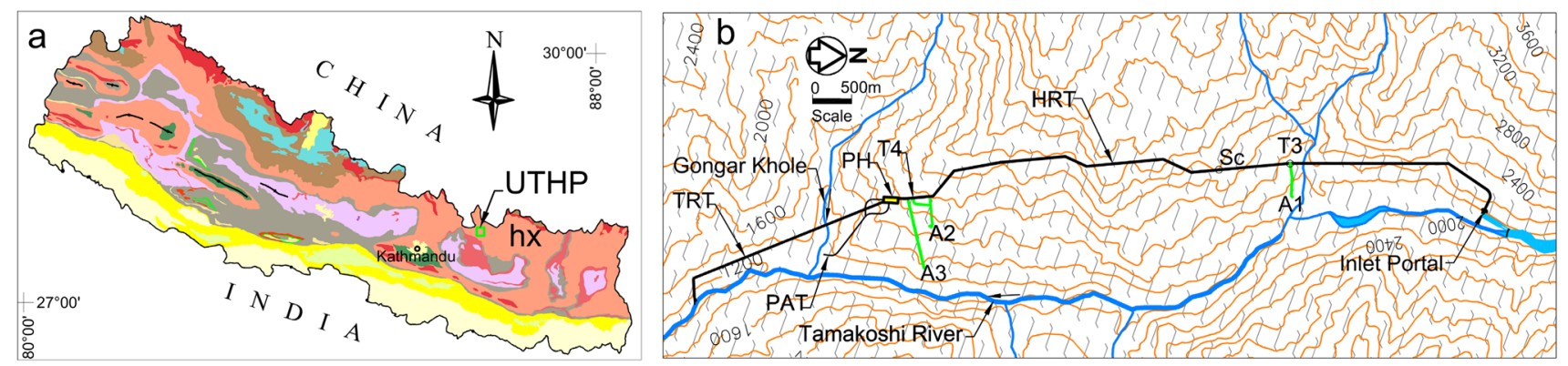

C

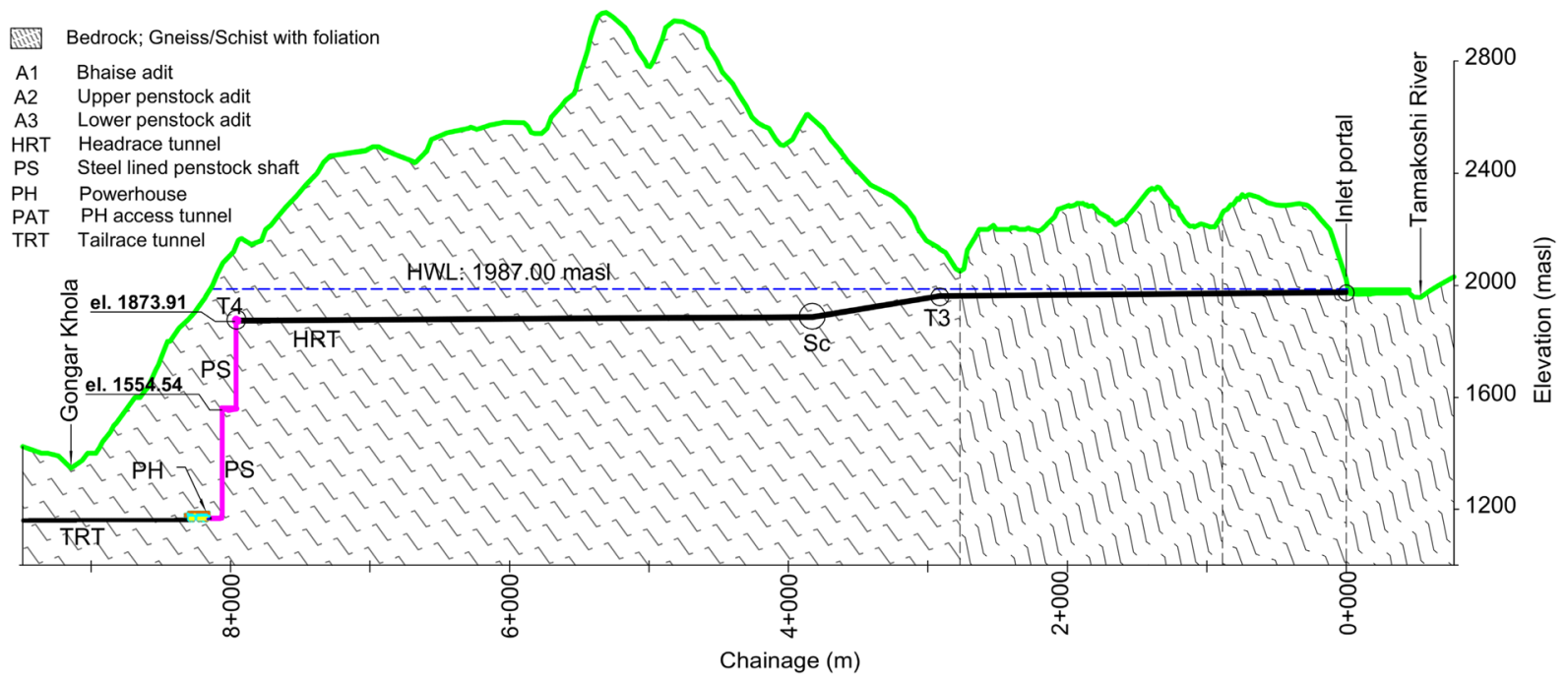

Fig. 3 a Location of the UTHP in geological map of Nepal; b Layout plan of the headrace tunnel; $\mathbf{c}$ The longitudinal profile along with the waterway system. NB in the figure, 'masl' is meters above sea level and 'HWL' is Head Water Level

of the project area during the feasibility study concluded that rock type in the project area is mainly characterized as schistose gneiss with the content of mineral mica (Norconsult 2005). Rock mass at the project area mainly consists of foliation joints and two distinct cross joint sets (Panthi and Basnet 2017). The general strikes of the foliation joints are ESE-WNW with dip angles of $35^{\circ}-75^{\circ}$ varying in direction between NE and NW (Fig. 4).

The orientation of joints with respect to the orientation of the length axis of a tunnel is an important expect for both tunnel stability and potential water leakage through an unlined or shotcrete lined pressure tunnel during operation. It is the fact that the joints that are perpendicular to the direction of the minimum principal stress are more vulnerable for hydraulic jacking. Therefore, emphasis should always be given to identify these joints while planning unlined pressure tunnels and shafts.

The characteristics of joints such as spacing, persistence, aperture and infilling conditions should be defined to understand both mechanical and hydraulic behavior of the joints. Basnet and Panthi (2020) studied joint details of the tunnel segment between T3 and T4 (Fig. 3c). The joints mapped along the tunnel in good quality rock mass are mostly tightly healed and intact excluding some cross joints that are filled with silty clay of thickness 1 to $2 \mathrm{~mm}$. In addition, quartz and feldspar veins of up to $20 \mathrm{~cm}$ thick are also observed occasionally within the foliation joints. The typical mean values of persistence and spacing of the joints are $2 \mathrm{~m}$ and $3 \mathrm{~m}$, respectively. The fractured rock mass on the other hand consists mainly joints filled with permeable silty clay of thickness exceeding $10 \mathrm{~mm}$. The thickness reaches up to $100 \mathrm{~mm}$ in those areas of the tunnel where local shear bands are developed within the rock mass along the foliation plane. The typical mean values of persistence and spacing of the joints are $10 \mathrm{~m}$ and $2 \mathrm{~m}$, respectively. In case of the weakness zones, the rock mass is sheared and heavily jointed. The joints are filled with silty clay. The joint persistence exceeds over $20 \mathrm{~m}$ and the joints are closely spaced with a typical spacing of about $1 \mathrm{~m}$.

\subsection{Rock Mass Quality Condition}

The rock mass quality along the headrace tunnel was mapped during tunnel excavation using Q-system of rock mass classification as defined by Barton et al. (1974). The rock mass quality mapped along the headrace tunnel alignment between chainage 

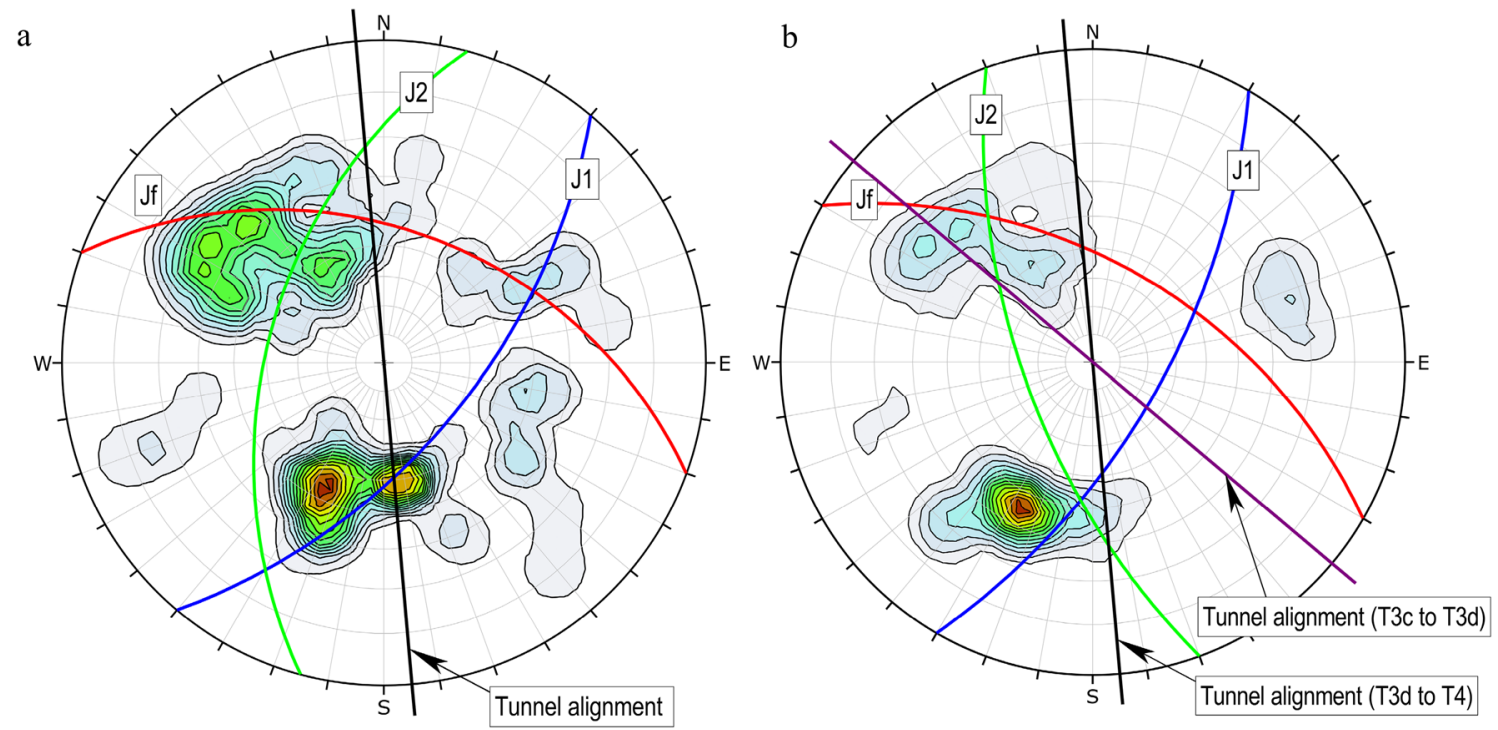

Fig. 4 Orientation of the joints and tunnel alignment; a Joints mapped from chainage $6+500 \mathrm{~m}$ to $6+800 \mathrm{~m}$ (Location A), b Joints mapped from T3c to T4 (Location B)

$2+914$ (T3) to chainage $7+960$ (T4) are shown in Fig. 5. As seen in Fig. 5, the rock mass quality along the headrace tunnel varied from good ( $Q$ values exceeding 4.0) to extremely poor
( $Q$ values having less than 0.1 ) rock mass quality. In the fractured or jointed rock mass, recorded $Q$ values ranged between 0.1 to 4.0 representing very poor to poor quality rock mass.

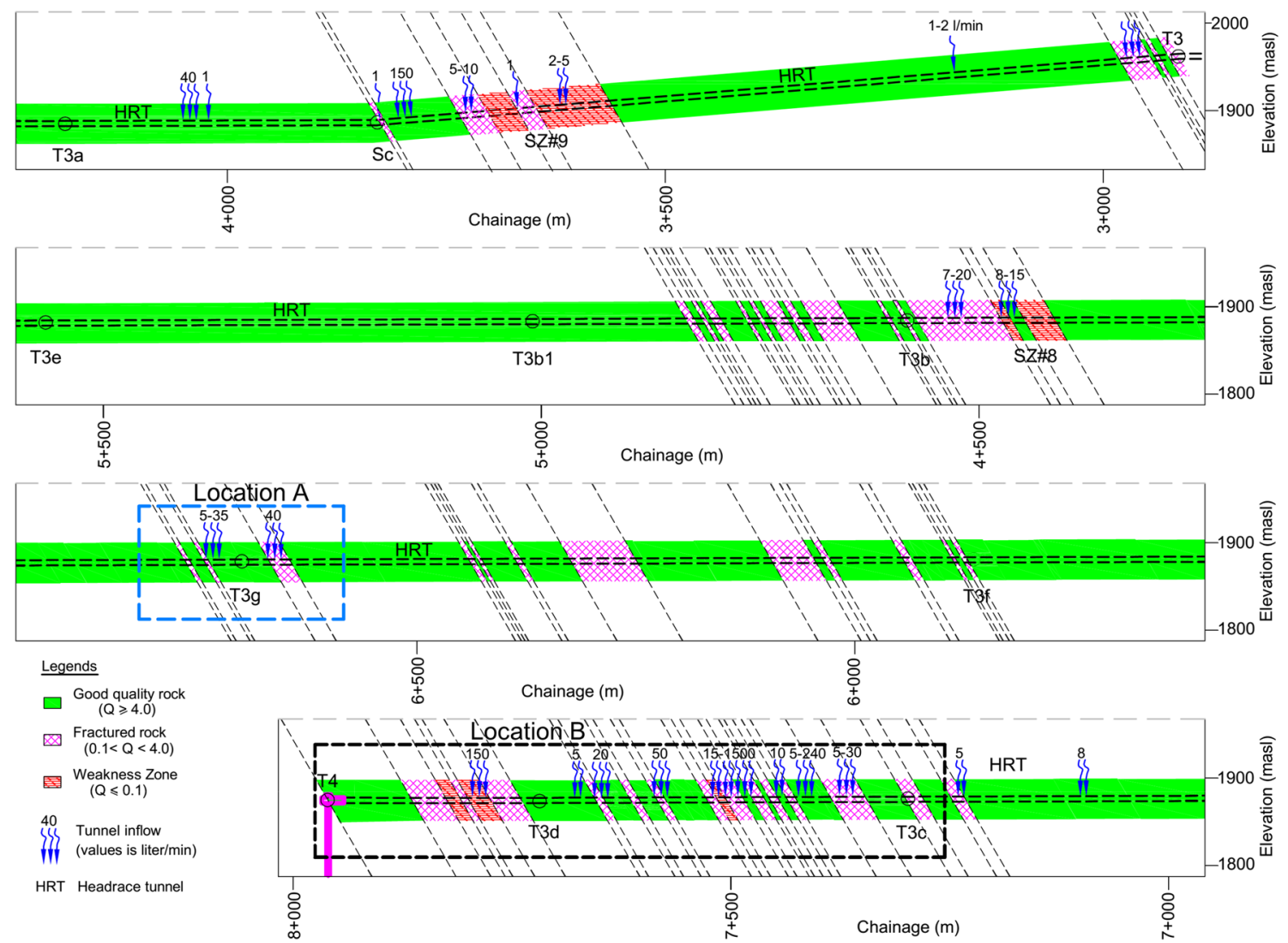

Fig. 5 Rock mass quality and inflow along the headrace tunnel registered during excavation [Updated in Basnet and Panthi (2020)] 
Similarly, crushed, weathered and clay mixed rock mass of the weakness zones have $Q$ values that ranged between 0.01 and 0.1 representing extremely poor rock mass quality. As one can observe in Fig. 5, almost 80 percent length of the headrace tunnel has good quality rock mass ( $Q$ values exceeding 4). Similarly, about $700 \mathrm{~m}$ length of the headrace tunnel has fractured rock mass ( $Q$ values between 0.1 and 4 ) and approximately $200 \mathrm{~m}$ tunnel length has extremely poor rock mass of the weakness zones ( $Q$ values below 0.1). It is highlighted that the rock mass at the downstream end of the headrace tunnel (downstream from chainage $7+300$ ) where hydrostatic water pressure will reach to its maximum of $1.15 \mathrm{MPa}$ (11.5 bars) during operation of the power plant is mainly dominated either by fractured rock mass or by extremely poor rock mass of the weakness zones.

Three different rock mass quality groups shown in Fig. 5 behave differently when exposed to high water pressure. The good quality rock mass is relatively resistive towards hydraulic fracturing/jacking if the minimum principal stress is higher than the hydrostatic water head (pressure). However, the fractured rock mass and rock mass of the weakness zones are vulnerable to hydraulic jacking and water leakage due to the presence of joints either open or filled with silty clay and sand.

\subsection{Rock Mass Weathering Condition}

According to Panthi (2006), rock weathering has great influence in the strength and deformability properties of the rock mass, and the extent of influence depends on the degree of weathering. Five different degree of rock mass weathering class were used while mapping the tunnel face during the excavation of the headrace tunnel following ISRM (1978c) weathering classification. The frequency distribution of the degree of weathering along headrace tunnel is presented in Fig. 6.

In the figure, ' $\mathrm{N}$ ' is total number of mapped tunnel segments. As one can see in the figure, good to very good rock mass falls within slightly weathered class (II) category, fractured rock mass mainly falls within moderately weathered class (III) category, and rock mass of the weakness zone falls in highly weathered (IV) to extremely weathered (V) class category. According to Panthi (2006), the degree of weathering influences greatly on the strength and modulus of elasticity of the intact rock, which is also indicated as reduction percentage $\left(P_{R}\right)$ of intact rock strength for each weathering grade.

\section{Parametric Study}

The parameters required for the analysis were estimated based on data achieved through various investigations such as laboratory testing, engineering geological field mapping,

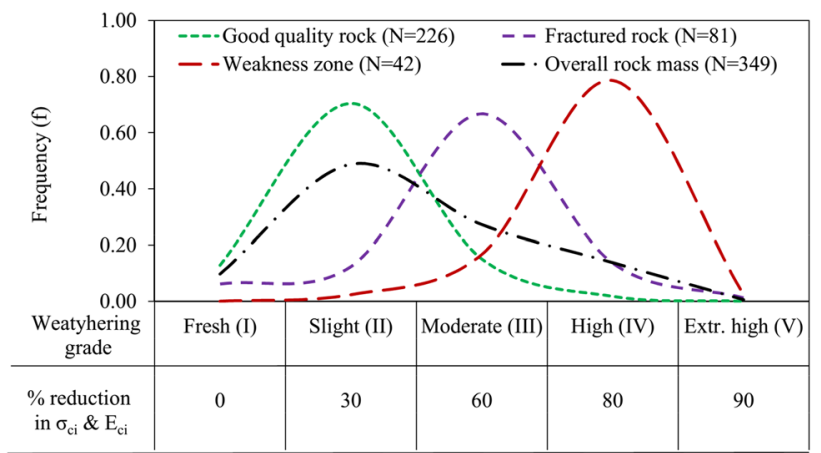

Fig. 6 Frequency distribution of weathering grade for different quality rock mass and percentage reduction $\left(P_{\mathrm{R}}\right)$ in intact rock strength and modulus of elasticity based on Panthi (2006)

geophysical and drilling investigations, mapping and testing carried out in exploratory adit, tunnel mapping and relevant published information.

\subsection{Rock Mechanical Properties}

The rock samples were collected during field mapping carried out in 2014 and 2016, which were tested at the Engineering Geology Laboratory of NTNU. Tested rock samples were extracted from different depths of the exploratory borehole 'ST-1' located near to the surge shaft. The diameter of the cores is about $50 \mathrm{~mm}$, which is the same test diameter as recommended by Bieniawski and Bernede (1979) and ISRM (1978a and 1978b). Several samples were tested to find out uniaxial compressive strength (UCS) and elastic modulus $\left(E_{\mathrm{ci}}\right)$ of the intact rock. Seven discs were tested to find out the tensile strength using Brazilian test. In addition, sound velocity and unit weight were also measured and determined. Table 1 lists statistical distribution of mechanical properties consisting UCS $\left(\sigma_{\mathrm{ci}}\right)$, modulus of elasticity $\left(E_{\mathrm{ci}}\right)$, Poisson's ratio $(\nu)$, unit weight $\left(\gamma_{\mathrm{r}}\right)$, sound velocity $\left(V_{\mathrm{s}}\right)$ and tensile strength $\left(\sigma_{\mathrm{t}}\right)$. In the table, ' $\Delta$ ' is an angle between schistosity plane and loading direction. It was observed during the UCS test that the failure occurred along schistosity plane of most of the tested cores.

According to Panthi (2006), uniaxial compressive strength of the intact rock specimen is smallest when schistocity plane is inclined at around 30 degrees from the loading direction. An average angle of about 31 degrees were measured during UCS testing, which is very close to the minimum intact rock strength.

\subsection{Rock Mass Parameters}

Rock mass deformation modulus is an important parameter to be estimated to assess the stiffness of the joints, which is required for UDEC analysis. Since rock mass along the 
Table 1 Rock mechanical properties of selected rock samples obtained from laboratory test

\begin{tabular}{lccccccc}
\hline Statistical value & $\sigma_{\mathrm{ci}}, \mathrm{MPa}$ & $E_{\mathrm{ci}}, \mathrm{GPa}$ & $\nu$ & $\Delta, \mathrm{deg}$ & $\gamma_{\mathrm{r}}, \mathrm{KN} / \mathrm{m}^{3}$ & $V_{\mathrm{s}}, \mathrm{m} / \mathrm{sec}$ & $\sigma_{\mathrm{t}}, \mathrm{Mpa}$ \\
\hline Min & 61.5 & 33.5 & 0.1 & 22 & 26.4 & 4295 & 9.0 \\
Mean & 105.3 & 45.8 & 0.2 & 31 & 26.8 & 4736 & 10.0 \\
Max & 182.6 & 60.4 & 0.3 & 35 & 27.8 & 5242 & 12.3 \\
Sd & 39.9 & 8.1 & 0.06 & 4 & 0.40 & 321 & 1.2 \\
\hline
\end{tabular}

Table 2 Rock mass deformability of the material at weakness zone estimated by different approaches

\begin{tabular}{|c|c|c|c|c|c|c|c|c|c|c|c|c|c|}
\hline \multirow[t]{2}{*}{ Statistical values } & \multirow{2}{*}{$\begin{array}{l}\sigma_{\mathrm{ci}} \\
\mathrm{MPa}\end{array}$} & \multirow{2}{*}{$\begin{array}{l}E_{\mathrm{ci}} \\
\mathrm{GPa}\end{array}$} & \multirow{2}{*}{$\begin{array}{l}\text { Weather- } \\
\text { ing grade }\end{array}$} & \multirow{2}{*}{$\begin{array}{l}P_{\mathrm{R}} \\
\%\end{array}$} & \multirow{2}{*}{$\begin{array}{l}\sigma_{\mathrm{ci}}^{\prime} \\
\mathrm{MPa}\end{array}$} & \multirow{2}{*}{$\begin{array}{l}E_{\mathrm{ci}}{ }^{\prime} \\
\mathrm{GPa}\end{array}$} & \multirow[t]{2}{*}{$Q$} & \multirow[t]{2}{*}{$\mathrm{RMR}^{\mathrm{a}}$} & \multirow[t]{2}{*}{$\mathrm{GSI}^{\mathrm{b}}$} & \multirow[t]{2}{*}{$Q_{\mathrm{c}}{ }^{*}$} & \multicolumn{3}{|c|}{ Rock mass deformability $\left(E_{\mathrm{m}}\right), \mathrm{GPa}$} \\
\hline & & & & & & & & & & & ${ }^{\mathrm{c}}$ Barton (2002) & $\begin{array}{l}{ }^{\mathrm{d}} \text { Hoek and } \\
\text { Diederichs } \\
\text { (2006) }\end{array}$ & ${ }^{\mathrm{e}}$ Panthi (2006) \\
\hline Min & 61.5 & 33.5 & - & 90 & 6.2 & 3.3 & 0.007 & 17 & 12 & 0.001 & 1.0 & 0.2 & 0.2 \\
\hline Mean & 110.1 & 47.2 & IV & 75 & 29.9 & 12.8 & 0.022 & 24 & 19 & 0.007 & 1.8 & 0.6 & 1.2 \\
\hline Max & 182.6 & 60.4 & - & 60 & 73.0 & 24.2 & 0.060 & 32 & 27 & 0.044 & 3.5 & 1.6 & 3.3 \\
\hline $\mathrm{Sd}$ & 39.9 & 8.1 & - & - & 13.1 & 3.7 & 0.014 & 3 & 3 & 0.008 & 0.5 & 0.3 & 0.6 \\
\hline
\end{tabular}

${ }^{*} Q_{\mathrm{c}}=Q \times \sigma_{\mathrm{ci}}{ }^{\prime} / 100$

${ }^{\mathrm{a}} \mathrm{RMR}=15 \log Q+50$

${ }^{\mathrm{b}} \mathrm{GSI}=\mathrm{RMR}-5$

${ }^{\mathrm{c}} E_{\mathrm{m}}=10 \times \mathrm{Q}_{\mathrm{c}}{ }^{1 / 3}$

${ }^{\mathrm{d}} E_{\mathrm{m}}=\mathrm{E}_{\mathrm{ci}}{ }^{\prime} \times\left(0.02+(1-D / 2) /\left(1+\mathrm{e}^{((60+15 \mathrm{D}-\mathrm{GSI}) / 11)}\right)\right.$

${ }^{\mathrm{e}} E_{\mathrm{m}}=1 / 60 \times \mathrm{E}_{\mathrm{ci}}{ }^{\prime} \times \sigma_{\mathrm{ci}}{ }^{,(0.5)}$

headrace tunnel is mainly represented by three rock mass quality groups, three different values of rock mass deformability were required to be calculated to represent respective rock mass quality group. Three different approaches representing Barton (2002), Hoek and Diederichs (2006) and Panthi (2006) were used to estimate rock mass deformation modulus. As indicated in Table 2, Barton (2002) uses $Q$ value and UCS while Hoek and Diederichs (2006) uses Geological Strength Index (GSI), disturbance factor $(D)$ and modulus of elasticity $\left(E_{\mathrm{ci}}\right)$ to estimate deformation modulus $\left(E_{\mathrm{m}}\right)$. RMR values were calculated using mapped $Q$ values following the relationship proposed by Barton (1995). GSI values were calculated using the equation proposed by Hoek and Diederichs (2006). To avoid subjectivity, Panthi (2006) recommends the direct use of UCS and modulus of elasticity for the calculation of rock mass deformation modulus. Intact rock strength $\left(\sigma_{\mathrm{ci}}\right)$ and modulus of elasticity $\left(E_{\mathrm{ci}}\right)$ were first converted to reduced intact rock strength $\left(\sigma_{\mathrm{ci}}{ }^{\prime}\right)$ and modulus of elasticity $\left(E_{\mathrm{ci}}{ }^{\prime}\right)$ to reflect the weathering degree in the intact rock. A calculation example for the rock mass of the weakness zone is presented in Table 2. The same principle was used for the calculation of rock mass deformation modulus for other two category rock mass; i.e. good quality rock mass and fractured rock mass.

Figure 7 presents calculated rock mass deformation modulus $\left(E_{\mathrm{m}}\right)$ for three different rock mass quality groups that was mapped along the headrace tunnel. As seen in the figure,

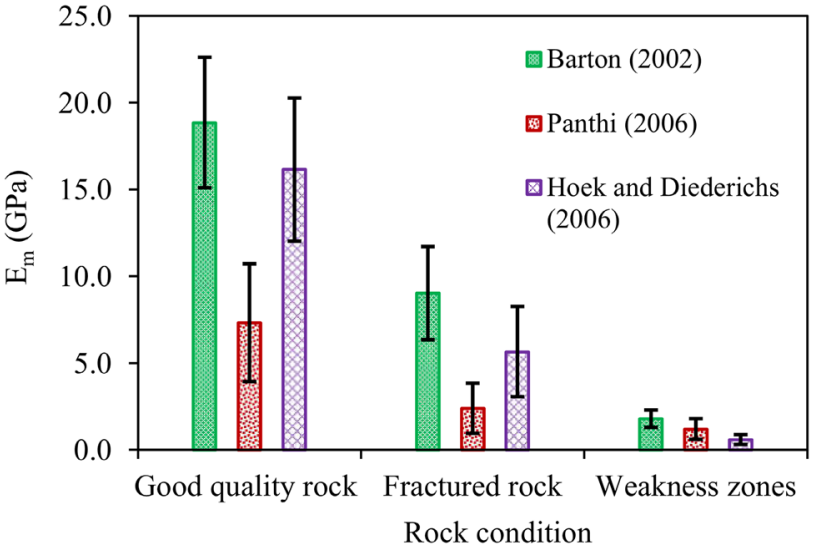

Fig. 7 Deformation modulus of rock mass calculated by three different approaches for different rock conditions (colored bar shows mean values; and vertical line with cap shows standard deviation, Sd.) (color figure online)

rock mass deformation modulus calculated using the relationship proposed by Barton (2002) gave upper limit values for all three rock mass categories. On the other hand, the relationship proposed by Panthi (2006) gave values in the lower range for both good quality rock mass and jointed rock mass while the relationship proposed by Hoek and Diederichs (2006) gave lower range value for the rock mass of the weakness zones. The deformation modulus calculated 
using relationship proposed by Hoek and Diederichs (2006) for both good quality and fractured rock mass, and values calculated using relationship proposed by Panthi (2006) for the rock mass of weakness zone were used for the analysis to avoid both optimistic and conservative estimation.

The bulk modulus of intact rock $\left(K_{\mathrm{ci}}\right)$ and rock mass $\left(K_{\mathrm{m}}\right)$ and the shear modulus of intact rock $\left(G_{\mathrm{ci}}\right)$ and rock mass shear modulus $\left(G_{\mathrm{m}}\right)$ were calculated using respective relationships (Table 3) proposed by Goodman (1989) for isotropic rock material. In UDEC, there exist several options that could be used as a constitutive model to define plastic behavior of the rock mass. Mohr-Coulomb failure criterion was used as constitutive model to define plastic behavior. The parameters that Mohr-Coulomb criterion uses are rock mass tensile strength $\left(\sigma_{\mathrm{tm}}\right)$, cohesion $(C)$, friction angle $(\Phi)$ and dilation angle. RocData software developed by RocScience (2018) was used to estimate $\sigma_{\mathrm{tm}}, C$, and $\Phi$. The material constants $\left(m_{\mathrm{i}}\right)$ for different rock mass qualities ere estimated from the values given in Marinos and Hoek (2000) for Gneiss rock $\left(m_{\mathrm{i}}=28 \pm 5\right)$. The authors describe that higher values of $m_{i}$ are associated with tightly interlocked crystalline rocks having higher frictional characteristics. Highest $m_{\mathrm{i}}$ values were therefore chosen for good quality rock mass and intermediate for fractured rock mass and lowest for rock mass of the weakness zones. Similarly, the value of the dilation angle is dependent on rock mass quality. According to Hoek and Brown (1997) the dilation angle is about onefourth of the friction angle for good quality rock mass; oneeighth of the frictional angle for relatively fractured rock mass (average quality rock mass) and close to zero for very poor to exceptionally poor rock mass of the weakness zones. Table 3 shows the estimated parameters for all three rock mass quality categories of the headrace tunnel.

\subsection{Joint Parameters}

Normal and shear stiffness of the joints are important input parameters that define the mechanical behavior of joints. The joint stiffness impacts on the hydraulic behavior in case hydro-mechanical coupling is carried out in UDEC. The joint stiffness was estimated using elastic properties of the adjacent rock mass. Barton (1972) and Singh (1973) recommended Eq. 8 and Eq. 9 to calculate joint normal and shear stiffness, respectively, were used.

$$
\begin{aligned}
& k_{n}=\frac{E_{c i}^{\prime} \times E_{m}}{J_{s} \times\left(E_{c i}^{\prime}-E_{m}\right)}, \\
& k_{s}=\frac{G_{c i} \times G_{m}}{J_{s} \times\left(G_{c i}-G_{m}\right)}
\end{aligned}
$$

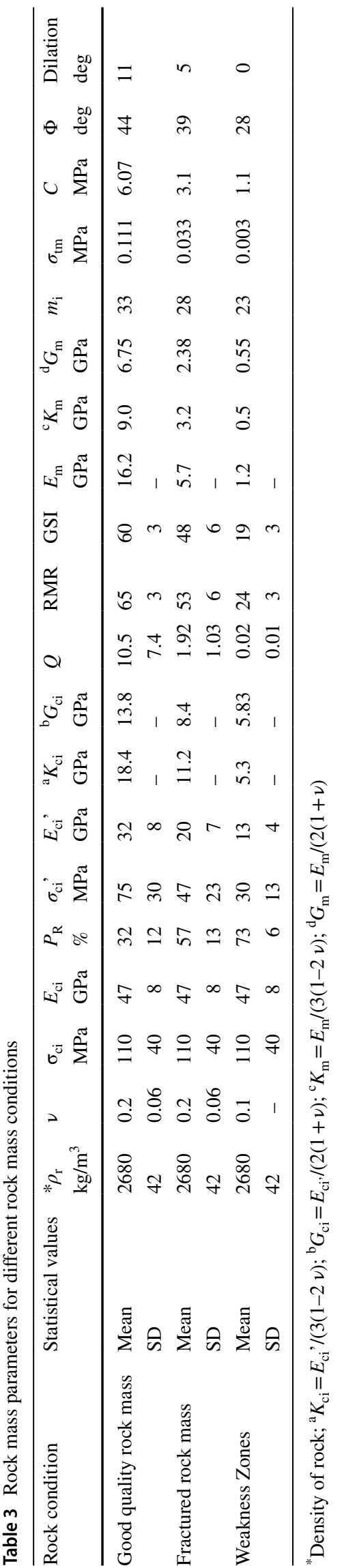


where $k_{n}$ is joint normal stiffness, $k_{s}$ is joint shear stiffness and $J_{s}$ is joint spacing. As discussed earlier, the joints are divided into three different categories, i.e. joints within good quality rock mass, fractured rock mass and rock mass of the weakness zones. To calculate joint stiffness, the average spacing of all joint sets were used in addition to young's modulus and rock mass modulus of each rock mass quality group. The estimated final values of all joint parameters are presented in Table 4.

Since Tamakoshi River originates from the Himalayan Glaciesr and the UTHP dam site is located at around $2100 \mathrm{~m}$ elevation, the average water temperature of about $10^{\circ} \mathrm{C}$ was assumed to calculate dynamic viscosity of water $(\mu)$. Similarly, the values for joint aperture $\left(a_{0}\right)$ was based on joint mapping along the headrace tunnel alignment.

\section{Stress State Analysis}

The data on mechanical properties and stress measurements at the UTHP area have been valuable information while evaluating in-situ stress state. At the UTHP, both 3D-overcoring (locations: TT1, TT2 and TT3) and hydraulic fracturing / hydraulic jacking (locations: 1, 2, 3, 4, 5, 6 and 7) techniques as shown in Fig. 8 were used to measure in-situ stress state. The measurements were carried out at three different elevation levels of the topography at different phases of design and construction. However, these data represent specific locations and may mislead the result in case directly used for the interpretation of larger rock mass (larger topographic coverage) area. In order to integrate these data for the analysis of the stress state of the UTHP area, a final rock stress model (FRSM) concept as recommended by Stephansson and Zang (2012) was extensively utilized.

According to Stephansson and Zang (2012) the FRSM concept considers the stepwise evaluation of the in-situ stress state integrating best estimate stress model (BESM), stress measurement methods (SMM) and integrated stress determination methods (ISD). Therefore, four steps were followed to develop the FRSM. First, three-dimensional geometry inside the model extent was generated in FLAC ${ }^{3 \mathrm{D}}$, where the model extent was chosen in such a way that it covered the stretch of pressure tunnel from $\mathrm{T} 3$ to $\mathrm{T} 4$ including stress measurement locations. Second, input parameters to the model were defined and uncertainties of different parameters were evaluated using gathered data and information. For that, the BESM established by Basnet and Panthi $(2019,2020)$ for the Tamakoshi area was extensively used. Third, the global misfit function was defined to express discrepancy between measured and predicted stresses by integrating the result from both 3D-overcoring and hydraulic fracturing techniques. Fourth, the global misfit was minimized to generate the best-fit model. The output from best-fit model was considered a best possible result for the NEW HRT alignment of UTHP.

Basnet and Panthi (2020) used FLAC ${ }^{3 \mathrm{D}}$ model to analyze in-situ stress state of UTHP area within the model extent as shown in Fig. 9a. A three-dimensional geometry was created in FLAC $^{3 \mathrm{D}}$ (Fig. 9b) and the weakness zones (crushed zones CZ\#1, CZ\#2 and CZ\#3 and shear zones SZ\#1 to SZ\#9) were also included in the stress state analysis. Parametric analysis was carried out to optimize the model by minimizing the misfit. For that, number of trials were used in the model and misfit was calculated for each trial. The magnitudes of the principal stresses measured at all measurement locations and corresponding simulated stresses obtained from the model at different trials including the optimized trial are presented in Fig. 10. The measured values are plotted with the error bars equal to one standard deviation on each side of the mean values. It was found that the difference between measured (mean) and simulated principal stresses are less than one standard deviation for more than $55 \%$ of the test data and are less than two standard deviations for more than $80 \%$ test data of the best fit model. Basnet and Panthi (2020) considered this result as an acceptable condition for the model to be valid.

Achieved magnitude of minimum principal stresses along the headrace tunnel alignment between $\mathrm{T} 3$ and $\mathrm{T} 4$ are shown in Fig. 11. As seen in the figure, there is a considerable stress attenuation nearby the shear zones along the headrace tunnel alignment. More importantly, the values of minimum principal stress are less than hydrostatic water pressure at weakness zones located at around chainage $3+600 \mathrm{~m}$, chainage $4+450 \mathrm{~m}$ and downstream from chainage $7+300 \mathrm{~m}$. The stress information presented in Fig. 11 was used to validate the UDEC model.

The detail rock engineering assessment carried out along the headrace tunnel alignment of UTHP indicated that the presence of long persisting joints and discontinuities at the fractured rock mass and rock mass of the weakness zones
Table 4 Joint parameters at different rock mass conditions of the UTHP

\begin{tabular}{|c|c|c|c|c|c|c|c|c|c|c|}
\hline Rock condition & $\begin{array}{l}E_{\mathrm{ci}} \\
\mathrm{GPa}\end{array}$ & $\begin{array}{l}G_{\mathrm{ci}} \\
\mathrm{GPa}\end{array}$ & $\begin{array}{l}E_{\mathrm{m}} \\
\mathrm{GPa}\end{array}$ & $\begin{array}{l}G_{\mathrm{m}} \\
\mathrm{GPa}\end{array}$ & $\begin{array}{l}J_{\mathrm{s}} \\
\mathrm{m}\end{array}$ & $\begin{array}{l}k_{\mathrm{n}} \\
\mathrm{Pa} / \mathrm{m}\end{array}$ & $\begin{array}{l}k_{\mathrm{s}} \\
\mathrm{Pa} / \mathrm{m}\end{array}$ & $\begin{array}{l}\mu \\
\mathrm{Pa} / \mathrm{s}\end{array}$ & $\begin{array}{l}k_{\mathrm{j}} \\
(\mathrm{Pa} / \mathrm{s})\end{array}$ & $\begin{array}{l}a_{0} \\
\mathrm{~m}\end{array}$ \\
\hline Good quality rock & 32.2 & 13.8 & 16.2 & 6.8 & 3.0 & $2.2 \mathrm{E}+09$ & $8.8 \mathrm{E}+08$ & $1.31 \mathrm{E}-03$ & 63.81 & $0-0.002$ \\
\hline Fractured rock & 20.2 & 8.4 & 5.7 & 2.4 & 2.0 & $7.9 \mathrm{E}+08$ & $3.3 \mathrm{E}+08$ & $1.31 \mathrm{E}-03$ & 63.81 & $0-0.01$ \\
\hline Weakness zone & 12.8 & 5.83 & 1.2 & 0.5 & 1.0 & $2.6 \mathrm{E}+08$ & $1.2 \mathrm{E}+08$ & $1.31 \mathrm{E}-03$ & 63.81 & $0-0.02$ \\
\hline
\end{tabular}




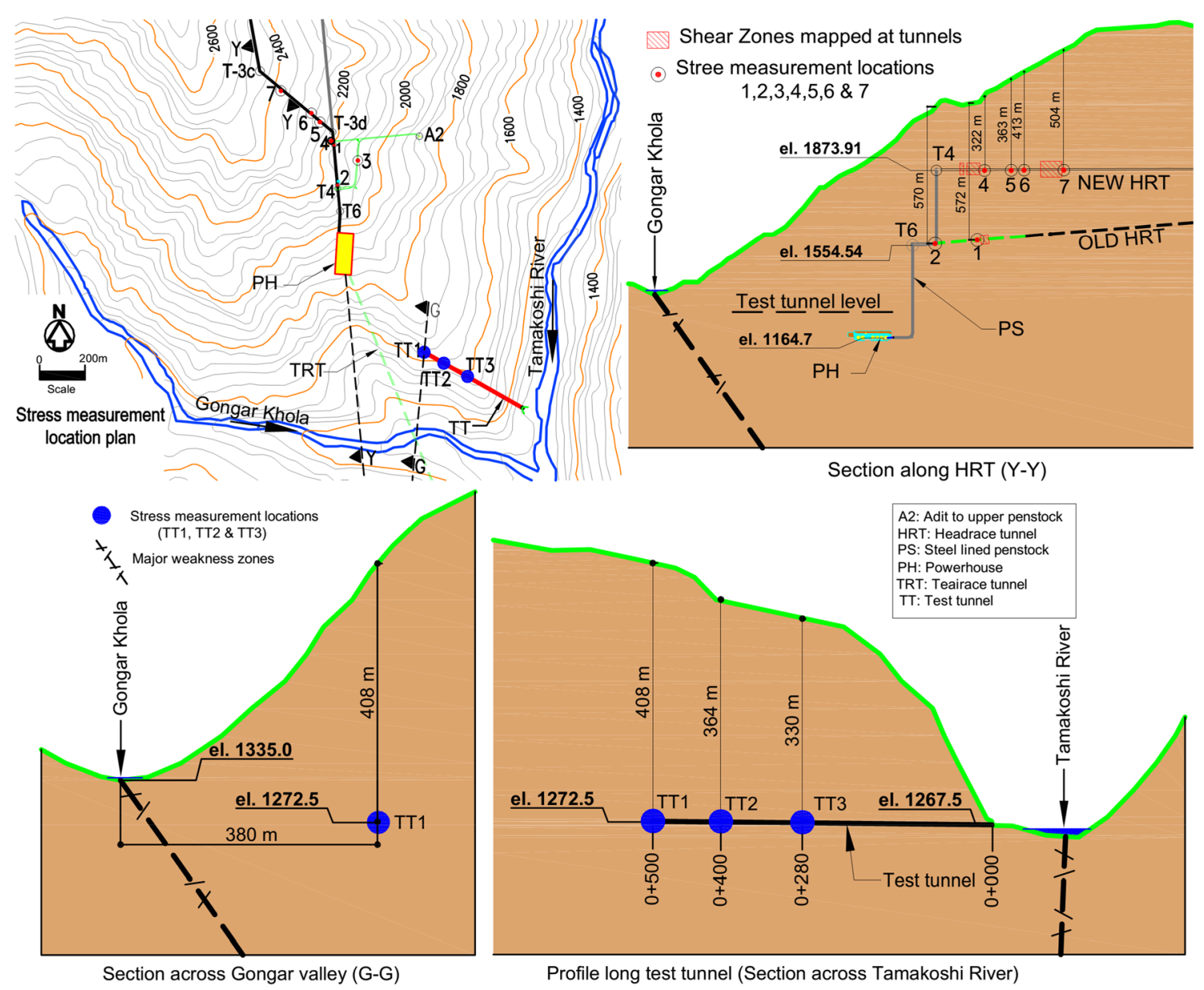

Fig. 8 Stress measurement locations TT1, TT2, TT3, 1, 2, 3, 4, 5, 6 and 7 (note: all dimensions are in meter) (Basnet and Panthi 2020)

Fig. 9 a Model extent overlaid in the map of the UTHP area. Source: www.earth.googl e.com); b 3D geometry built-in FLAC3D with grids and potential weakness zones (Basnet and Panthi 2020)
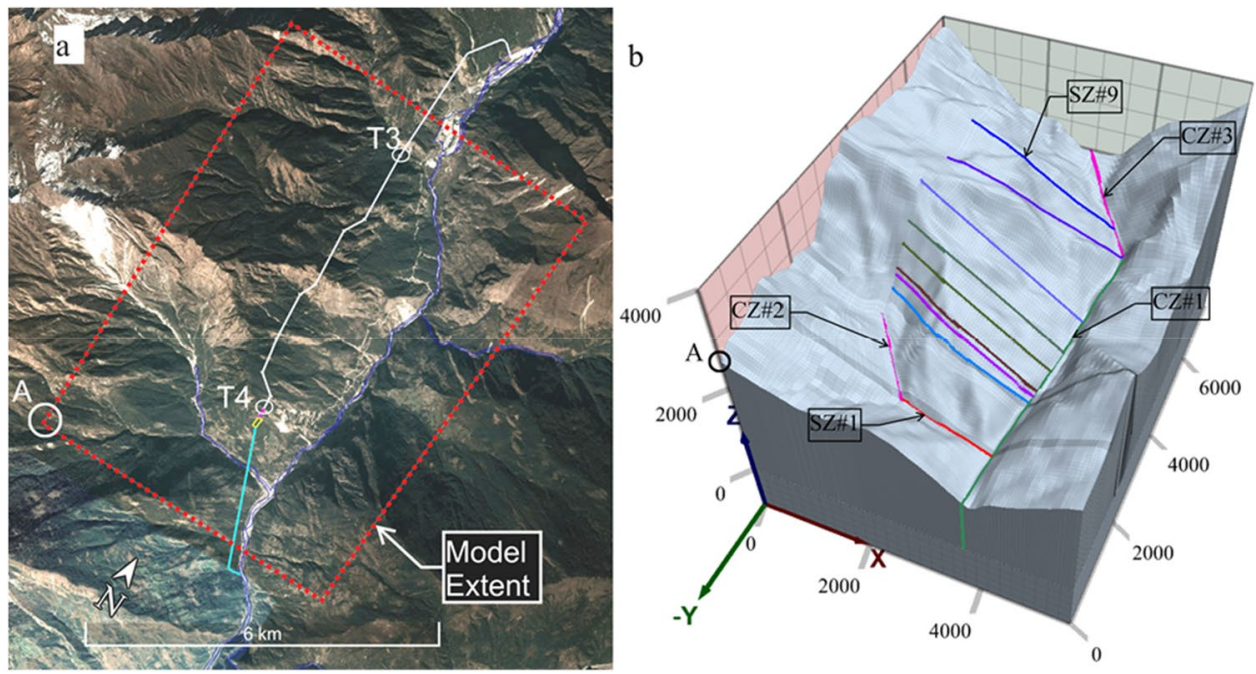

increase the vulnerability against hydraulic jacking and water leakage during tunnel operation even if both Norwegian overburden criteria and minimum principal stress magnitude criteria were satisfied (Basnet and Panthi, 2020).
Similar conclusions were also drawn by Basnet and Panthi (2018b) by analyzing selected waterways of some Norwegian hydropower projects. Therefore, fluid flow analysis was carried out at selected sections (locations A and B in 

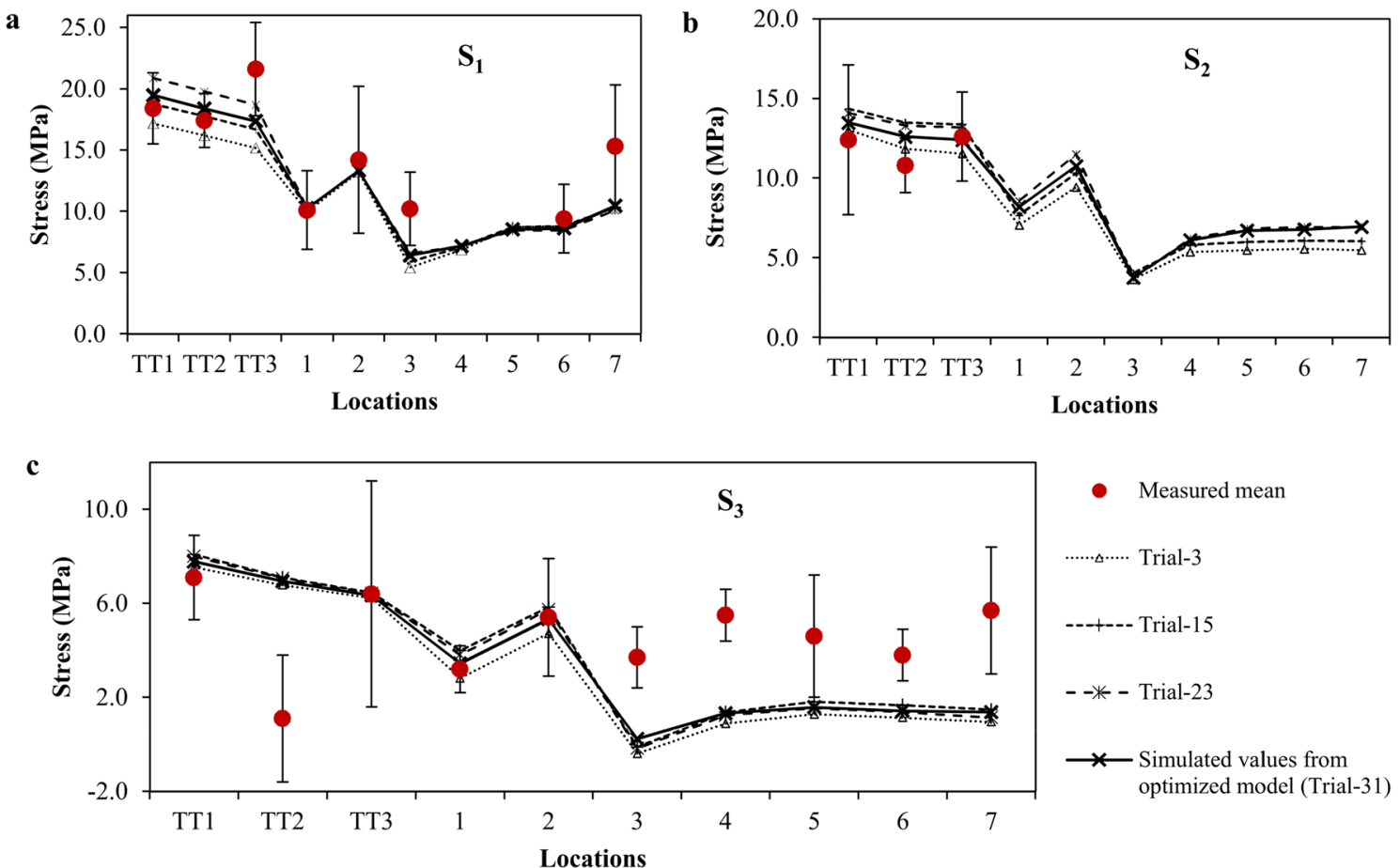

Fig. 10 The measured and simulated principal stresses; a maximum principal stress (S1); b intermediate principal stress (S2); c minimum principal stress (S3) (Basnet and Panthi, 2020)

Fig. 11 a. Simulated minimum principal stress along the headrace tunnel alignment between $\mathrm{T} 3$ and $\mathrm{T} 4, \mathrm{~b}$. minimum principal stress magnitude and static water pressure $\left(P_{\mathrm{w}}\right)$ along the headrace tunnel alignment between T3 and T4 (Basnet and Panthi 2020)
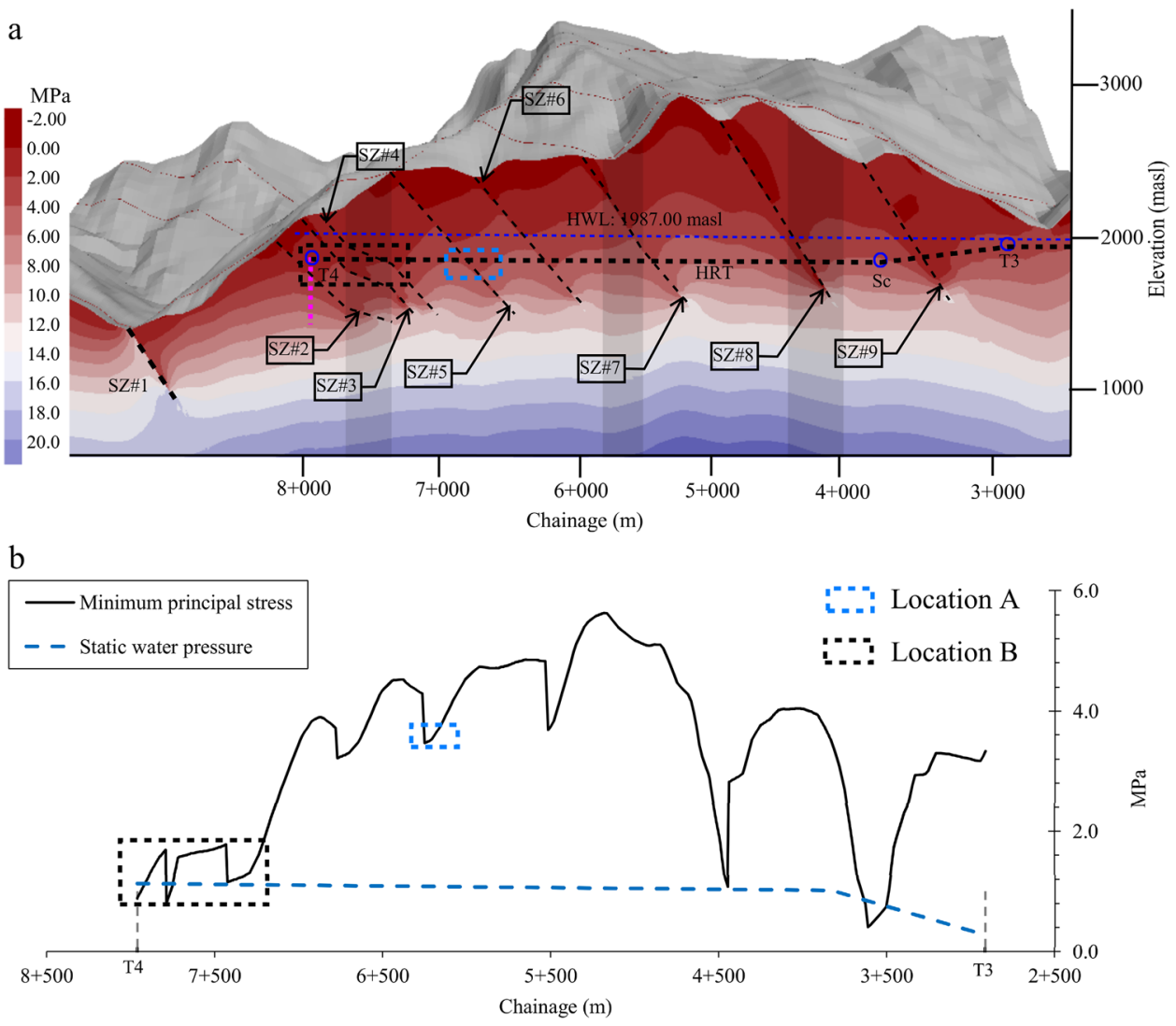
Figs. 5 and 11) using discontinuous model (UDEC) to assess potential hydraulic jacking through pre-existing joints. In terms of stress criteria, the tunnel alignment at Location A was found to be safe against hydraulic jacking whereas

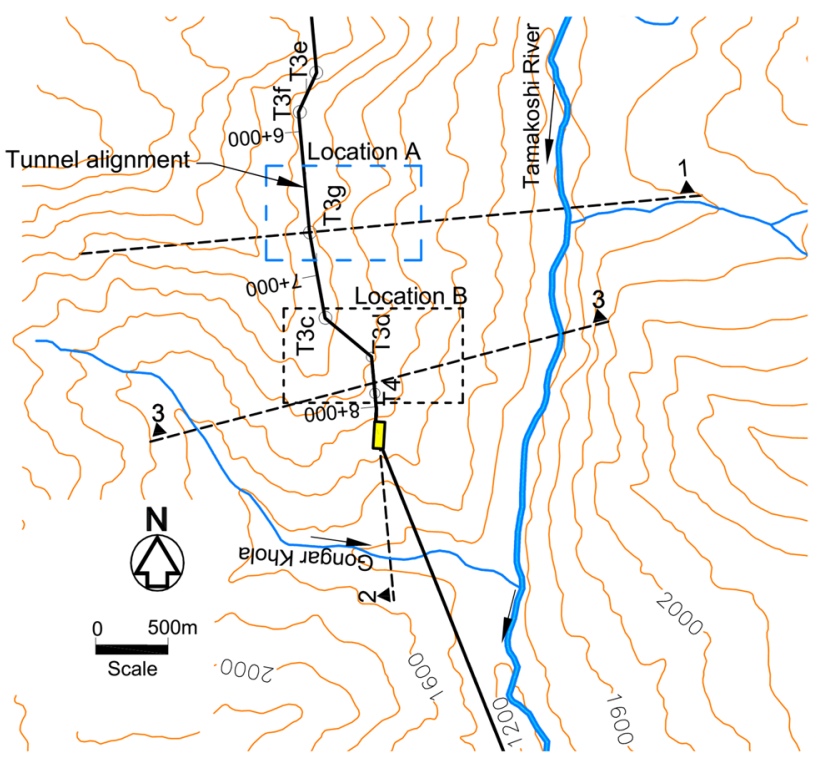

Fig. 12 Section lines at study locations A and B tunnel segment at Location B was found to be vulnerable for hydraulic jacking.

\section{Fluid Flow Analysis}

Since UDEC model is two dimensional, different sections along and across the tunnel alignment at selected Location A and Location B (Figs. 5 and 11) were carefully chosen to study fluid flow behavior of joints. The topographic section lines are shown in Fig. 12. The rock mass of these two locations has three joint sets. Since it was not possible to include all three joint sets in the selected section, the joint sets showing cross communication were modeled in the UDEC.

The topographic sections were first drawn based on the topographic map (Fig. 12) of the Tamakoshi area. The geometry in the UDEC model (Fig. 13) was then generated using topographic sections and jointing information. In Sect. 1-1 (Fig. 13a) and Sect. 3-3 (Fig. 13c), the foliation joints $\left(J_{\mathrm{f}}\right)$ and cross joint set $\left(J_{2}\right)$ were implemented whereas in Sect. 2-2 (Fig. 13b), the foliations joints $\left(J_{\mathrm{f}}\right)$, cross joint set $\left(J_{1}\right)$, and an unfavorable cross joint were implemented.

The assigned properties of rock mass and joints shown Tables 3 and 4 were used as input variables. The stress along $Y$-axis was generated by gravity itself and the bottom of the model was fixed against displacement. The boundary stress
Fig. 13 Two-dimensional geometry, jointing and excavated locations (blue color) implemented in the UDEC model; a Section 1-1; b Section 2-2 and c Section 3-3
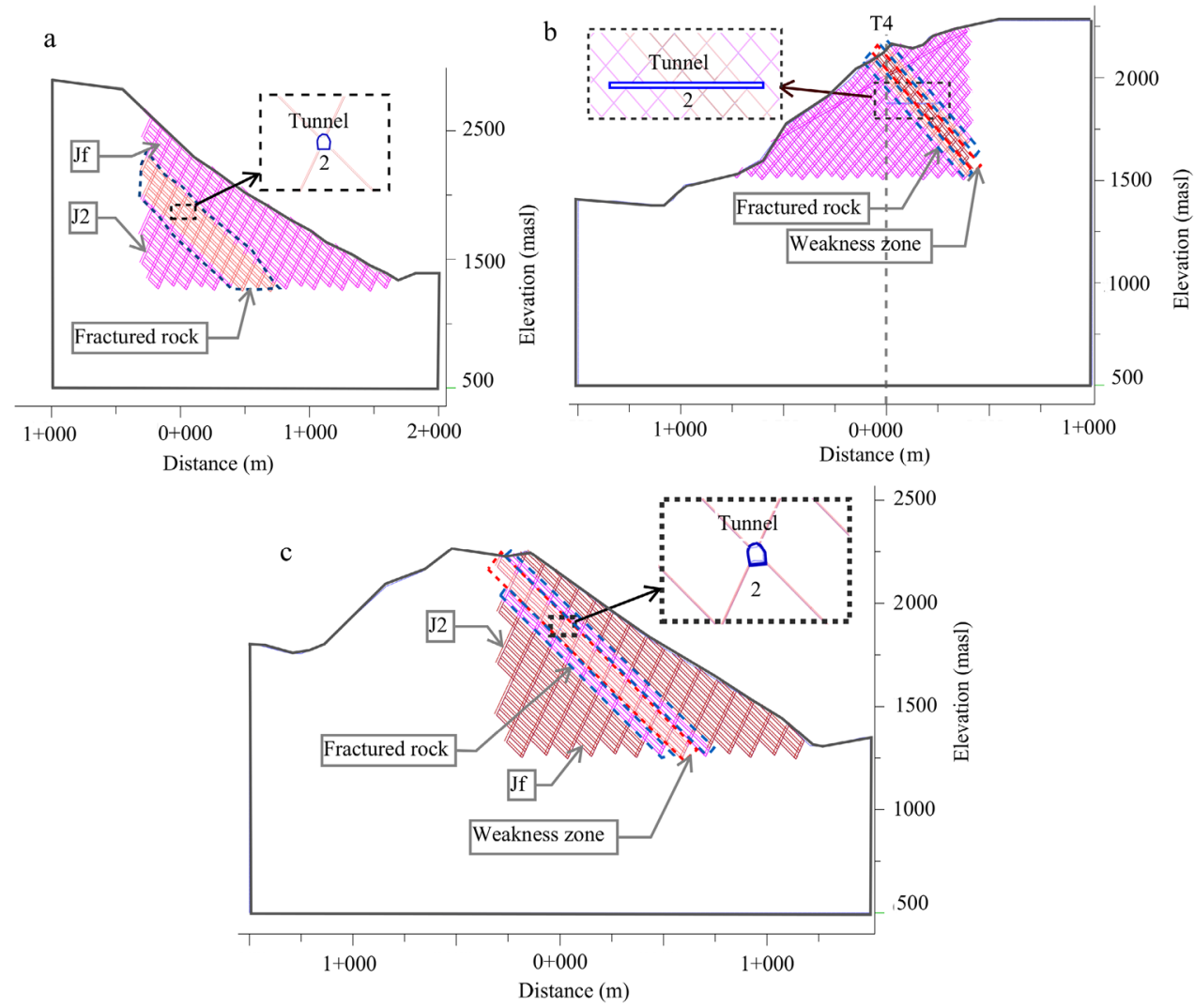
along $X$-axis was changed until the magnitude of minimum principal stress at tunnel locations became closer to the values as shown in Fig. 11 for respective sections. All the boundaries except surface topography were made impermeable against fluid flow. Mohr-Coulomb constitutive model was used to define the behavior of the blocks and Coulomb slip model (joint area contact) was used to define behavior of the joints.

After the geometry was created and the boundary conditions was fixed, the UDEC model was run until it converged to mechanical equilibrium. Fluid (water) pressure at the excavated segments (Fig. 13) was then assigned and the maximum fluid pressure was restricted to a maximum pressure of $1.15 \mathrm{MPa}$ (11.5 bars) caused by hydrostatic water head at the respective positions. The model was run once again until total fluid flow time was reached. Domain pore pressure developed after the end of total fluid flow time for all three sections are shown in Fig. 14. As shown in the figure, different positions were selected to track the pore pressure built up along the joints and to assess potential hydraulic jacking, which may lead to the water leakage towards topographic slope.

The occurrence of hydraulic jacking was identified by initial pressure built-up and pressure drops after it reached to the corresponding hydrostatic head or even before. Figure 15a shows pore pressure built-up at different joint positions of Sect. 1-1 of the Location A over specified fluid flow time. As can be seen in Fig. 15a, considerable pressure built-up reached at positions 3 and 4 (Fig. 14a) after a certain fluid flow time elapsed indicating an initial sign of hydraulic jacking. The pressure reached to about one $\mathrm{MPa}$ (10 bars) which is not that far away from the maximum hydrostatic head of $1.15 \mathrm{MPa}$ (11.5 bars). The pressure slightly dropped at around $12 \mathrm{~s}$ of the flow time and increased to around one MPa (10 bars) for the rest of the fluid flow time. It is noted here that small drop in the pressure signifies an event of hydraulic jacking. On the other hand, small waves of pore pressure developed at positions 7 and 8 show repetitive development events of hydraulic jacking at these positions. Since the observed extent of hydraulic jacking at these positions was relatively small,

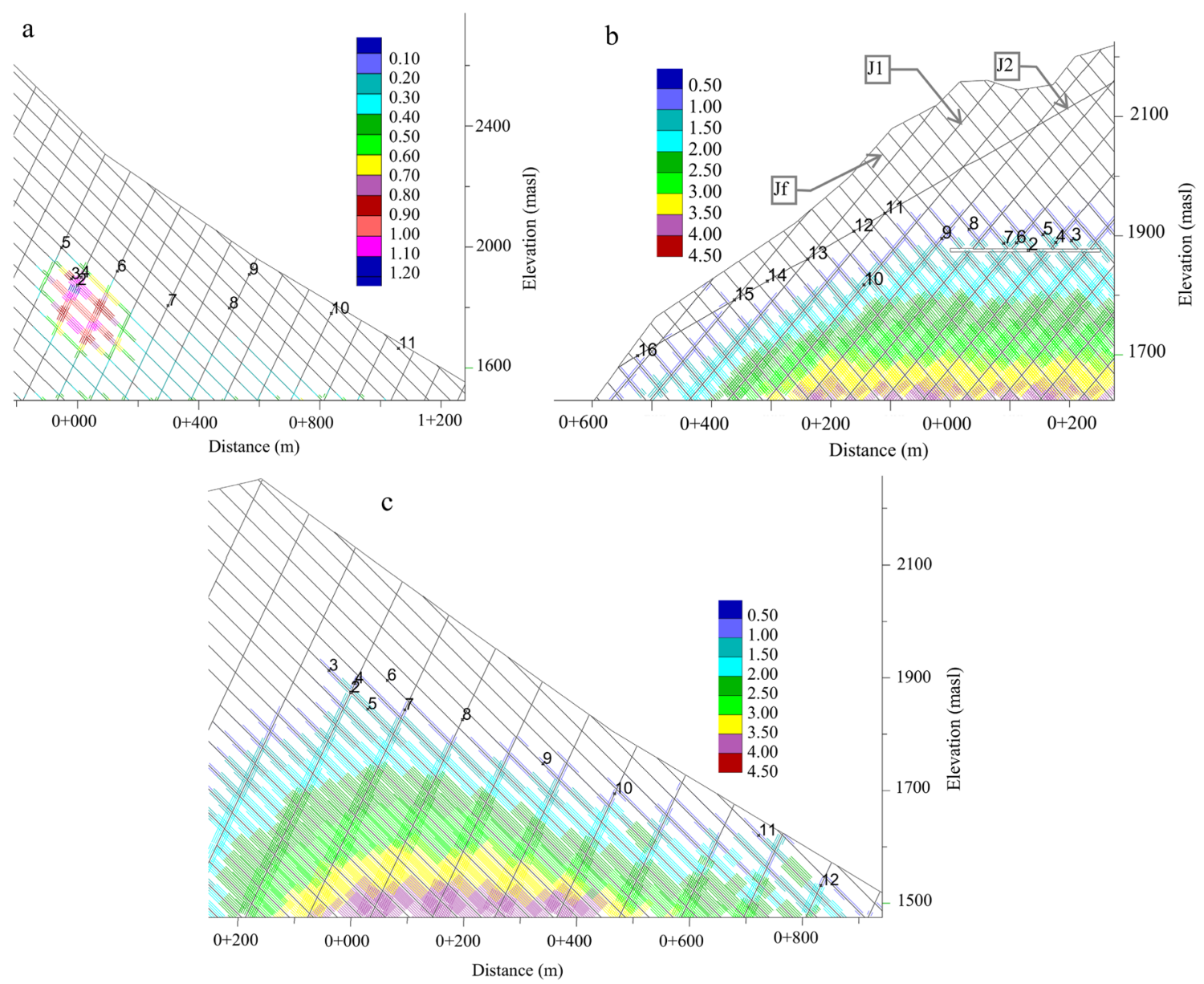

Fig. 14 Pore pressure in MPa developed at tracking locations at the end of flow time; a Section 1-1; b Section 2-2 and c Section 3-3 

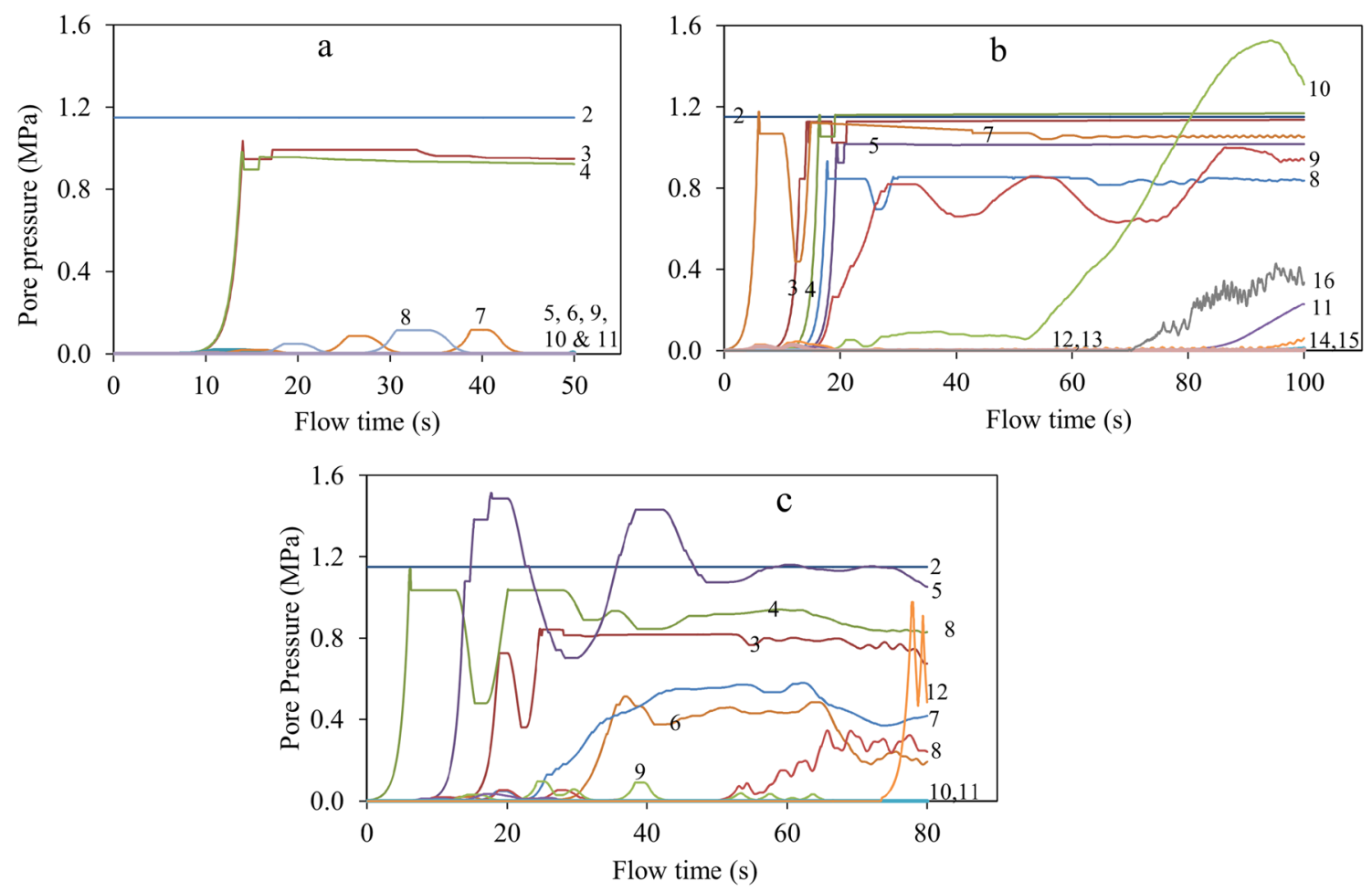

Fig. 15 Pore pressure vs fluid flow time tracked at different locations; a Section 1-1; b Section 2-2 and c Section 3-3

the extent of fluid flow from these positions was assumed to be insignificant. Similarly, almost negligible pressure was developed at the remaining tracking positions indicating no sign of hydraulic jacking.

Figure 15b shows pore pressure built-up at different joint positions of Sect. 2-2 at Location B where the hydrostatic water pressure reaches to its maximum of $1.15 \mathrm{MPa}(11.5$ bars). The pore pressure built up was registered at positions $3,4,5,7$ and 8 indicating signs of hydraulic jacking in the joints. The series of pressure built-up and dropdown signified pronounced hydraulic jacking in most of these positions. Likewise, the pressure built-up at positions 11 and 16 at the end of fluid flow time indicated the start of hydraulic jacking after a time lag. Similarly, Fig. $15 \mathrm{c}$ shows pore pressure built-up at different joint positions of Sect. 3-3 at Location B. As seen in the figure, the sequence of pressure built-up and pressure drop at positions 3, 4, 5, 6, 7, 8, 9 and 12 clearly indicated the occurrence of hydraulic jacking in the joints.

The fluid flow assessment carried out at Location A and Location B indicated that there is a possibility of hydraulic jacking through pre-existing joints in the rock mass which may lead to water leakage through the shotcrete lined headrace tunnel of UTHP. Location B (Figs. 5, 11b and 13) of the headrace tunnel (downstream from chainage $7300 \mathrm{~m}$ ) is most vulnerable headrace tunnel segment from where water leakage may occur. Since fluid flow analysis carried out using UDEC only indicates potential hydraulic jacking and possible water flow through joints but not the leakage amount from the tunnel, a leakage assessment was carried out using Panthi (2006) approach discussed at Sect. 2 (Brief review on fluid flow and leakage).

\section{Leakage Assessment}

Fluid flow analysis using UDEC represents a qualitative assessment and thus is an indication on potential leakage. Pore pressure developed along the joints indicated potential hydraulic jacking and flow of water through the joint systems leading to the potential leakage out from the tunnel through interlinked joint systems in the rock mass. It is a known fact that a shotcrete lined pressure tunnel (as is the headrace tunnel of UTHP) is not possible to construct in such a way that it is completely free from water leakage. Still, it is possible to limit the extent of leakage to a certain limit by using modern ground improvement technique such as pre- and post-injection grouting as discussed by Panthi (2013). Merritt (1999) recommends a specific leakage of $0.3 \mathrm{l} / \mathrm{min} / \mathrm{m}$ tunnel for the unlined or shotcrete lined water tunnels, which is practically not feasible to achieve in shotcrete lined pressure tunnel constructed through the Himalayan rock mass. The cost related to leakage control will turn out to be much higher than a pressure tunnel fully lined with concrete or steel. Panthi (2006) recommends a leakage limit 
of maximum up to $1.5 \mathrm{l} / \mathrm{min} / \mathrm{m}$ tunnel, which is achievable through ground improvements and is cost-effective as well. A proper leakage assessment is thus an important part of the study for shotcrete lined pressure tunnel of UTHP project so that adequate decision can be made to bring the leakage within the specified limit as suggested by Panthi (2006).

The leakage analysis presented below was carried out considering that the natural groundwater table (GWT) depletes to its minimum to almost at the headrace tunnel level of UTHP during the dry season of the year (from November to April). The hydrostatic water head created by flowing water in the headrace tunnel will, therefore, function as maximum groundwater table (GWT) in the rock mass during the dry season and will govern the extent of water leakage that may occur from the headrace tunnel out to the topographic surface. On the other hand, the groundwater table reaches to its maximum (almost to the ground surface of the topography) during monsoon (rainfall) season (from May to October) of the year. Therefore, the risk of potential water leakage from the headrace tunnel of UTHP will mainly be during the dry season of the year (from November to April). It is highlighted here that there is a lean (minimum) flow in the Himalayan rivers during the dry season and a single liter of water is valuable for run-of-river hydropower plant like UTHP.

\subsection{Overall Leakage Scenario from T3 to T4}

A quantitative leakage assessment was carried out using Panthi $(2006,2010)$ approach described in Sect. 2. The novelty of the leakage assessment at UTHP is that the leakage assessment process uses both Eq. 6 which was proposed by Panthi (2006) and published in Rock Mechanics and Rock Engineering in 2010 (Panthi and Nilsen 2010) and Eq. 7 (Panthi 2010) that describes joint permeability factor which was not fully developed when Panthi (2006) approach was published in Rock Mechanics and Rock Engineering (Panthi and Nilsen 2010). The leakage assessment covers total headrace tunnel length of $5045 \mathrm{~m}$ from T3 and T4 (Figs. 3 and 5). As seen in Fig. 3, there is a drastic change on hydrostatic water head downstream from T3 of the headrace tunnel which varies from $0.29 \mathrm{MPa}$ (2.9 bars) at T3 to $1.15 \mathrm{MPa}$ (11.5 bars) at T4. A total number of 487 mapped rock mass quality data from $\mathrm{T} 3$ to $\mathrm{T} 4$ of the headrace tunnels were used for the leakage assessment. Statistical values of different rock mass jointing parameters $\left(J_{\mathrm{p}}, J_{\mathrm{s}}, J_{\mathrm{n}}, J_{\mathrm{r}}\right.$ and $\left.J_{\mathrm{a}}\right)$ for three different rock mass quality groups, shortest distance to the topographic surface $(D)$, hydrostatic water head $(H)$, and calculated values of permeability factor $\left(f_{\mathrm{a}}\right)$ and specific leakage $\left(q_{\mathrm{t}}\right)$ are presented in Table 5 .

As Table 5 indicates, out of $5045 \mathrm{~m}$ headrace tunnel, $4245 \mathrm{~m}$ headrace tunnel passes through good quality rock mass having $Q$ values above 4, $705 \mathrm{~m}$ tunnel passes through fractured rock mass having $Q$ values between 0.1 to 4 and $95 \mathrm{~m}$ tunnel passes through rock mass of the weakness and shear zones having $Q$ values less than 0.1 . The average specific leakage through the tunnel having good quality rock mass was found to be $1.1 \mathrm{1} / \mathrm{min} / \mathrm{m}$ tunnel, which is within the acceptable limit. On the other hand, the average specific leakage from the headrace tunnel segments with fractured

Table 5 Results of leakage assessment from T3 to T4 of headrace tunnel at full hydrostatic pressure

\begin{tabular}{|c|c|c|c|c|c|c|c|c|c|c|c|}
\hline \multirow[t]{2}{*}{ Rock mass quality class } & \multirow{2}{*}{$\begin{array}{l}\text { Tunnel length } \\
\mathrm{m}\end{array}$} & \multirow[t]{2}{*}{ Statistical value } & \multirow{2}{*}{$\begin{array}{l}J_{\mathrm{p}} \\
\mathrm{m}\end{array}$} & \multirow{2}{*}{$\begin{array}{l}J_{\mathrm{s}} \\
\mathrm{m}\end{array}$} & \multirow{2}{*}{$\begin{array}{l}D \\
\mathrm{~m}\end{array}$} & \multirow{2}{*}{$\begin{array}{l}f_{\mathrm{a}} \\
1 / \mathrm{min} / \mathrm{m}^{2}\end{array}$} & \multirow{2}{*}{$\begin{array}{l}H \\
\mathrm{~m}\end{array}$} & \multicolumn{3}{|c|}{$\begin{array}{l}\text { Rock mass } \\
\text { parameters }\end{array}$} & \multirow{2}{*}{$\begin{array}{l}q_{\mathrm{t}} \\
1 / \mathrm{min} / \mathrm{m}\end{array}$} \\
\hline & & & & & & & & $J_{\mathrm{n}}$ & $J_{\mathrm{r}}$ & $J_{\mathrm{a}}$ & \\
\hline \multirow[t]{4}{*}{ Good quality rock mass $(Q \geq 4.0)$} & \multirow[t]{4}{*}{4245} & Min & & 2 & 144 & 0.0013 & 29 & 3 & 1 & 0.8 & 0.2 \\
\hline & & Mean & 2 & 3 & 400 & 0.0018 & 91 & 6 & 1.8 & 2,2 & 1.1 \\
\hline & & Max & & 4 & 533 & 0.0046 & 115 & 12 & 3 & 6.0 & 4.3 \\
\hline & & $\mathrm{Sd}$ & & & 101 & 0.0007 & 27 & 2 & 0.7 & 0.8 & 0.9 \\
\hline \multirow[t]{4}{*}{ Fractured rock $(0.1<Q<4.0)$} & \multirow[t]{4}{*}{705} & Min & & 1 & 135 & 0.0077 & 15 & 6 & 0.5 & 3 & 0.4 \\
\hline & & Mean & 10 & 2 & 439 & 0.0135 & 53 & 8 & 1.6 & 4.3 & 4.1 \\
\hline & & Max & & 3 & 652 & 0.0370 & 90 & 18 & 3 & 8 & 21.9 \\
\hline & & $\mathrm{Sd}$ & & & 143 & 0.0071 & 17 & 2 & 0.6 & 1 & 3.1 \\
\hline \multirow[t]{4}{*}{ Weakness zone $(Q \leq 0.1)$} & \multirow[t]{4}{*}{95} & Min & & 0.5 & 260 & 0.0468 & 10 & 9 & 0.5 & 5 & 5.5 \\
\hline & & Mean & 25 & 1 & 483 & 0.0533 & 26 & 13 & 1 & 8.4 & 7.6 \\
\hline & & Max & & 1.5 & 534 & 0.0961 & 65 & 15 & 1 & 10 & 12.8 \\
\hline & & $\mathrm{Sd}$ & & & 65 & 0.0117 & 13 & 3 & 0.1 & 1 & 1.7 \\
\hline \multirow[t]{4}{*}{ Overall rock mass } & \multirow[t]{4}{*}{5045} & Min & 2 & 0.5 & 135 & 0.0013 & 28 & 3 & 0.5 & 0.8 & 0.2 \\
\hline & & Mean & 12 & 2 & 415 & 0.0090 & 93 & 7 & 1.7 & 3 & 2.5 \\
\hline & & $\operatorname{Max}$ & 25 & 4 & 651 & 0.0961 & 115 & 18 & 3 & 10 & 21.9 \\
\hline & & $\mathrm{Sd}$ & & & 112 & 0.0152 & 25 & 4 & 0.7 & 2 & 2.8 \\
\hline
\end{tabular}


rock mass and rock mass of the weakness zones was found to be 4.1 and $7.6 \mathrm{l} / \mathrm{min} / \mathrm{m}$ tunnel, respectively, which is much higher than the acceptable leakage limit as recommended by Panthi (2006). Table 5 also shows an average specific leakage of $2.5 \mathrm{l} / \mathrm{min} / \mathrm{m}$ tunnel through $5045 \mathrm{~m}$ headrace tunnel between $\mathrm{T} 3$ and $\mathrm{T} 4$, which indicates a total leakage exceeding 210 l/s. This leakage value is substantial for the high head project like UTHP with a net water head exceeding $800 \mathrm{~m}$ ( 80 bars). The overall leakage distribution through the headrace tunnel between T3 and T4 is presented in Fig. 16.

As seen in Fig. 16, the risk of highest leakage potential will be from the most downstream part of the headrace tunnel; i.e. from chainage $7+100 \mathrm{~m}$, between chainage $3+550 \mathrm{~m}$ to $3+800 \mathrm{~m}$ and at around chainage $4+500 \mathrm{~m}$.

\subsection{Leakage Scenario Downstream ch. 7100 m}

The most vulnerable headrace tunnel segment regarding water leakage will therefore be the $860 \mathrm{~m}$ segment downstream from chainage $7+100 \mathrm{~m}$ where considerably high spikes in the leakage values were obtained at this headrace tunnel segment (Figs. 16 and 17). An average specific leakage of about $5.5 \mathrm{1} / \mathrm{min} / \mathrm{m}$ tunnel was estimated to occur from this tunnel segment, which may result in over $80 \mathrm{l} / \mathrm{s}$ leakage. The fluid flow analysis carried out using UDEC at Location B (Figs. 12, 14 and 15) also indicated high-pressure build-up and potential hydraulic jacking, which correlates well with the leakage assessment results presented in Fig. 17. Hence, the downstream part of the headrace tunnel from chainage $7+100 \mathrm{~m}$ represents a potential scenario of

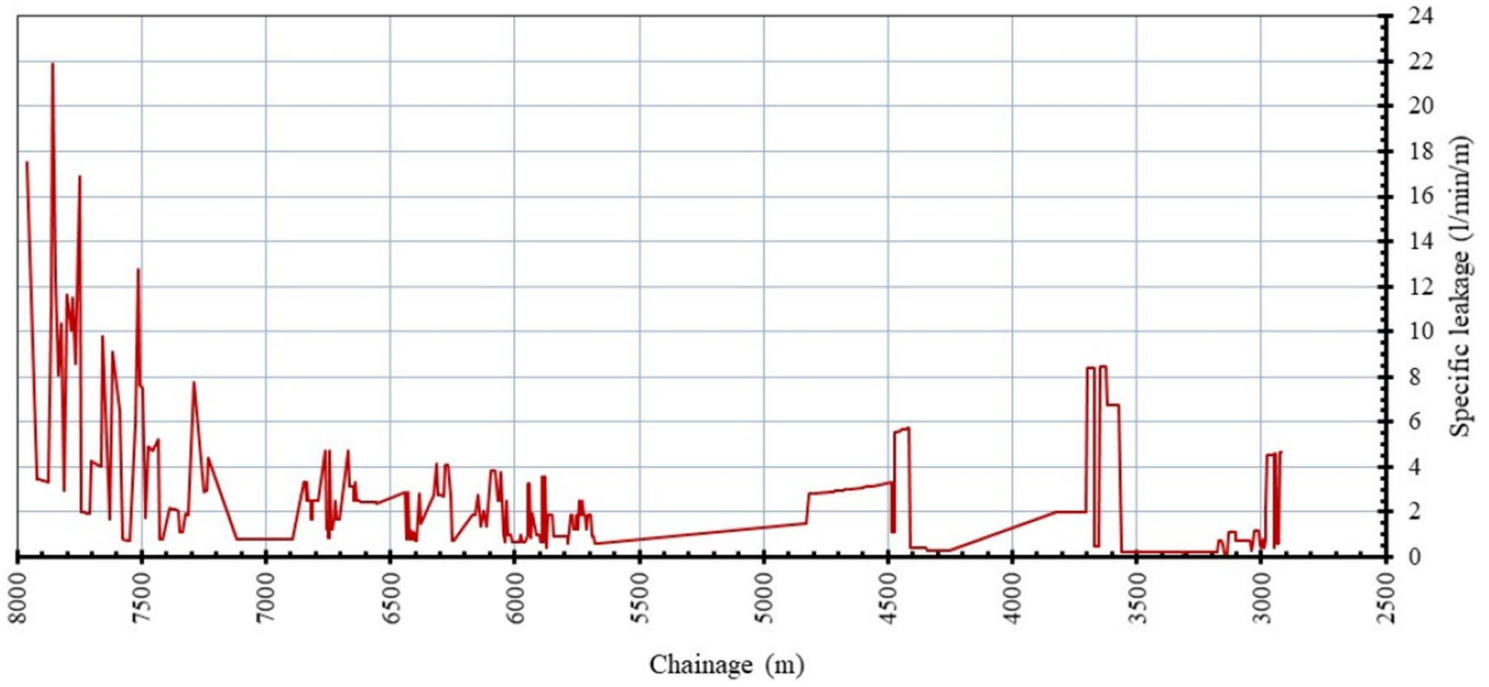

Fig. 16 Specific leakage distribution along $5045 \mathrm{~m}$ long the headrace tunnel between T3 and T4

Fig. 17 Specific leakage distribution downstream chainage $7100 \mathrm{~m}$ of the headrace tunnel

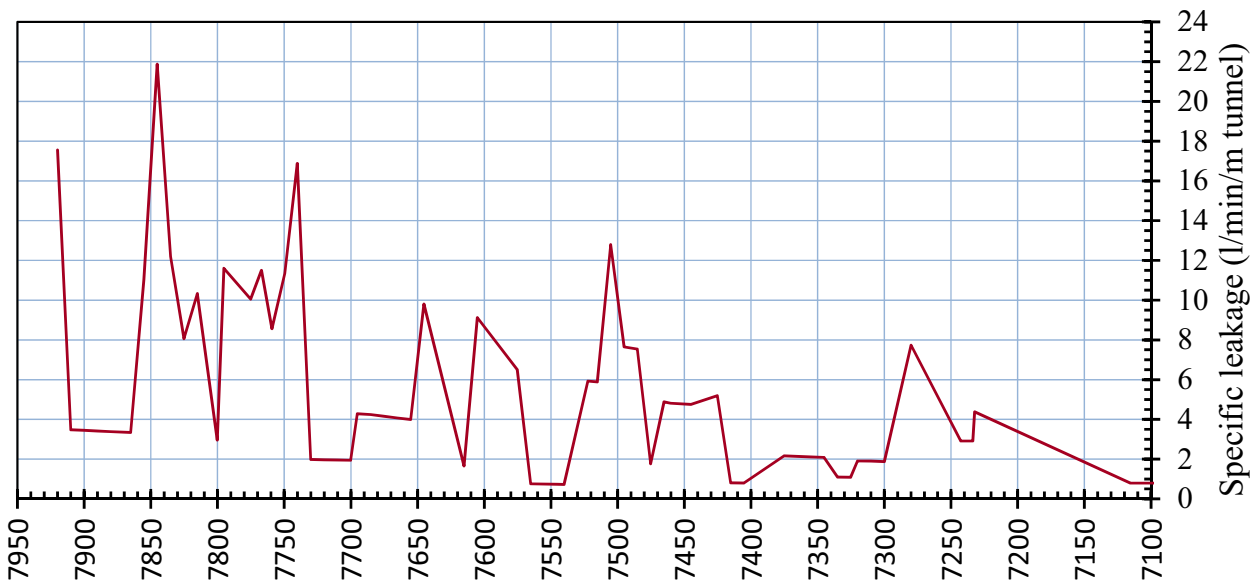

Chainage (m) 
the adverse situation regarding potential leakage at UTHP headrace tunnel.

The obtained leakage values along $860 \mathrm{~m}$ downstream segment of the headrace tunnel and some other short segments of headrace tunnel shown in Figs. 16 and 17 needed to be treated against water leakage to bring average specific leakage to an acceptable limit.

\subsection{Uncertainty in Leakage Assessment}

The leakage assessment method proposed by Panthi (2006) exploits three $Q$ value parameters consisting of joint set number $\left(J_{\mathrm{n}}\right)$, joint roughness number $\left(J_{\mathrm{r}}\right)$ and joint alteration number $\left(J_{\mathrm{a}}\right)$. The quantification of $J_{\mathrm{n}}$ and $J_{\mathrm{r}}$ values are relatively straight forward during tunnel mapping and are relatively less subjective. However, the quantification of $J_{\text {a }}$ needs special care and attention during tunnel mapping so that the true nature of the joint infilling condition is established, which is a tricky and subjective task and pose certain level of uncertainty in comparison to other two parameters. Especially, this is the case in a tunnel excavated with drill and blasting. It is, therefore, expected that the leakage estimation presented in this manuscript may vary to some extent from place to place. However, the overall pattern of the leakage through the headrace tunnel is believed to be not that far from reality in condition that no further water leakage treatment is carried out at the downstream stretch (downstream from chainage $7+100 \mathrm{~m}$ ) of the headrace tunnel. It is highlighted here that Panthi (2006) approach of leakage estimation is a well tested and verified method which was developed based on the real database of a tunnel project where the main author worked as construction manager, for details reference is made to Panthi (2006) and Panthi and Nilsen (2010).

\section{Conclusions}

The fluid flow assessment carried out using UDEC showed that open joints and joints filled with silt and clay having low stiffness are vulnerable for hydraulic jacking and pose a risk for water leakage out from a pressure tunnel even though the stress conditions are fulfilled. The fluid flow assessment carried out at Location A (downstream chainage 7+300 m) showed that there is a higher risk of pressure built-up and subsequent hydraulic jacking leading to excessive leakage from the headrace tunnel of UTHP. It is noted here that the fluid flow analysis using UDEC gives a qualitative indication of potential leakage and is a good source of information which could be used to carry out quantitative leakage assessment using Panthi $(2006,2010)$ approach. The quantitative leakage assessment carried out for $5045 \mathrm{~m}$ long headrace tunnel segment between T3 and T4 estimated an average leakage of $2.5 \mathrm{l} / \mathrm{min} / \mathrm{m}$ tunnel leading over $210 \mathrm{l} / \mathrm{s}$ water leakage from the headrace tunnel. More importantly, an average specific leakage of $5.5 \mathrm{l} / \mathrm{min} / \mathrm{m}$ tunnel for the $860 \mathrm{~m}$ downstream segment of the headrace tunnel is believed to be extremely high. Over $80 \mathrm{l} / \mathrm{s}$ leakage may occur only from this $860 \mathrm{~m}$ tunnel segment and is highly vulnerable regarding water leakage if no reliable remedial measures are taken at this downstream part of the headrace tunnel segment of UTHP.

Acknowledgements The authors are grateful to the project management team of Upper Tamakoshi Hydroelectric Project for providing project data and information and giving permission to carry out research on this project, which will be a milestone in the use of unlined pressure tunnel concept in the Himalayan region.

Funding Open Access funding provided by NTNU Norwegian University of Science and Technology (incl St. Olavs Hospital - Trondheim University Hospital)

Open Access This article is licensed under a Creative Commons Attribution 4.0 International License, which permits use, sharing, adaptation, distribution and reproduction in any medium or format, as long as you give appropriate credit to the original author(s) and the source, provide a link to the Creative Commons licence, and indicate if changes were made. The images or other third party material in this article are included in the article's Creative Commons licence, unless indicated otherwise in a credit line to the material. If material is not included in the article's Creative Commons licence and your intended use is not permitted by statutory regulation or exceeds the permitted use, you will need to obtain permission directly from the copyright holder. To view a copy of this licence, visit http://creativecommons.org/licenses/by/4.0/.

\section{References}

Barton N (1972) A model study of rock-joint deformation. Int J Rock Mech Min Sci Geomech Abstr 9(5):579-602

Barton N (1995) The influence of joint properties in modelling jointed rock masses. In: 8th ISRM congress

Barton N (2002) Some new $Q$ value correlations to assist in site characterization and tunnel design. Int J Rock Mech Min Sci 39(2): 185-216

Barton N, Lien R, Lunde J (1974) Engineering classification of rock masses for the design of tunnel support. Rock Mech 6(4):189-236

Basnet CB, Panthi KK (2018a) Roughness evaluation in shotcrete-lined water tunnels with invert concrete based on cases from Nepal. J Rock Mech Geotech Eng 10(1):42-59

Basnet CB, Panthi KK (2018b) Analysis of unlined pressure shafts and tunnels of selected Norwegian hydropower projects. J Rock Mech Geotech Eng 10(3):1-27

Basnet CB, Panthi KK (2019) Evaluation on the minimum principal stress state and potential hydraulic jacking from the shotcrete lined pressure tunnel-a case from Nepal. Rock Mech Rock Eng 52(7):2377-2399

Basnet CB, Panthi KK (2020) Detailed assessment on the use of unlined or shotcrete lined pressure tunnel in the Himalayan rock mass conditions: a case study from Nepal. Bull Eng Geol Env 79(1):153-184 
Bieniawski ZT, Bernede MJ (1979) ISRM suggested methods for determining the uniaxial compressive strength and deformability of rock materials. Int J Rock Mech Min Sci Geomech Abst 16(2):137-140

Broch, E., 1982. The development of unlined pressure shafts and tunnels in Norway. In: Proceedings of the International Symposium, International Society for Rock Mechanics (ISRM); pp 545-54.

Goodman RE (1989) Introduction to rock mechanics, vol 2. Wiley, New York, p 576

Hoek E, Brown ET (1997) Practical estimates of rock mass strength. Int J Rock Mech Min Sci 34(8):1165-1186

Hoek E, Diederichs M (2006) Empirical estimation of rock mass modulus. Int J Rock Mech Min Sci 43(2):203-215

ISRM (1978a) Suggested method for determining sound velocity. Int J Rock Mech Min Sci Geomech Abst. International Society for Rock Mechanics (ISRM): commission on standardization of laboratory and field tests, 15(1), pp 55-58.

ISRM (1978b) Suggested method for determining indirect tensile strength by the Brazil test. Int J Rock Mech Min Sci Geomech Abst 15(2):102-103

ISRM (1978c) Suggested methods for the quantitative description of discontinuities in rock mass. Int J Rock Mech Min Sci Geomech Abst 15:319-368

ITASCA, 2017. ITASCA Consulting Group, Inc. https://www.itasc acg.com

Kestin J, Sokolov M, Wakeham WA (1978) Viscosity of liquid water in the range -8 to $150{ }^{\circ} \mathrm{C}$. J Phys Chem Ref Data 7(3):941-948

Lamas LN, Leitão NS, Esteves C, Plasencia N (2014) First infilling of the Venda Nova II unlined high-pressure tunnel: observed behaviour and numerical modelling. Rock Mech Rock Eng 47(3):885-904

Louis C (1969) A study of groundwater flow in jointed rock and its influence on the stability of rock masses. Imperial Coll Rock Mech Res Rep 10:1-90

Marinos P, Hoek E (2000) GSI: a geologically friendly tool for rock mass strength estimation. In: ISRM international symposium. International Society for Rock Mechanics

Merritt, A.H., 1999. Geologic and geotechnical considerations for pressure tunnel design. Geo-Engineering for Underground Facilities, ASCE; pp.66-81.
Norconsult (2005) Feasibility study report of Upper Tamakoshi Hydroelectric Project, for the Nepal Electricity Authority, Nepal

Palmstrom A, Broch E (2017) The design of unlined hydropower tunnels and shafts: 100 years of Norwegian experience. Int J Hydropower Dams 3:1-9

Panthi KK (2006) Analysis of engineering geological uncertainties related to tunnelling in Himalayan rock mass conditions. $\mathrm{PhD}$ Thesis, NTNU, Trondheim, Norway

Panthi KK (2010) Note on estimating specific leakage using Panthi's approach. NTNU, Trondheim

Panthi KK (2013) Pre-injection versus post-injection grouting-a review of a case from the Himalaya. In: Proceedings: ARMA 2013

Panthi KK (2014) Norwegian design principle for high pressure tunnels and shafts: its applicability in the Himalaya. J Water Energy Environ 14:36-40

Panthi KK, Basnet CB (2017) Design review of the headrace system for the Upper Tamakoshi project Nepal. Int J Hydropower Dams 24(1):60-67

Panthi KK, Nilsen B (2010) Uncertainty analysis for assessing leakage through water tunnels: a case from Nepal Himalaya. Rock Mech Rock Eng 43(5):629-639

Rocscience (2018) RocData in Rocscience package https://www.rocsc ience.com

Singh B (1973) Continuum characterization of jointed rock masses: Part I-the constitutive equations. Int J Rock Mech Min Sci Geomech Abst 10(4):311-335

Stephansson O, Zang A (2012) "ISRM suggested methods for rock stress estimation-part 5: establishing a model for the in-situ stress at agiven site.” In: ISRM Suggested Methods for Rock Characterization, Testing and Monitoring: 2007-2014 pp 187-201

Publisher's Note Springer Nature remains neutral with regard to jurisdictional claims in published maps and institutional affiliations. 